\title{
Microbial Degradation of Plastics and Approaches to Make It More Efficient
}

\author{
I. B. Kotova ${ }^{a}$, Yu. V. Taktarova ${ }^{a}$, E. A. Tsavkelova ${ }^{a}$, M. A. Egorova ${ }^{a}$, I. A. Bubnov ${ }^{a}$, D. V. Malakhova ${ }^{a}$, \\ L. I. Shirinkina ${ }^{a}$, T. G. Sokolova ${ }^{b}$, and E. A. Bonch-Osmolovskaya ${ }^{a, b}$, * \\ ${ }^{a}$ Moscow State University, Moscow, 119234 Russia \\ ${ }^{b}$ Winogradsky Institute of Microbiology, Research Center of Biotechnology, Russian Academy of Sciences, \\ Moscow, 117312 Russia \\ *e-mail: elizaveta.bo@gmail.com
}

Received August 1, 2021; revised August 2, 2021; accepted August 2, 2021

\begin{abstract}
The growing worldwide production of synthetic plastics leads to increased amounts of plastic pollution. Even though microbial degradation of plastics is known to be a very slow process, this capacity has been found in many bacteria, including invertebrate symbionts, and microscopic fungi. Research in this field has been mostly focused on microbial degradation of polyethylene, polystyrene, and polyethylene terephthalate (PET). Quite an arsenal of different methods is available today for detecting processes of plastic degradation and measuring their rates. Given the lack of generally accepted protocols, it is difficult to compare results presented by different authors. PET degradation by recombinant hydrolases from thermophilic actinobacteria happens to be the most efficient among the currently known plastic degradation processes. Various approaches to accelerating microbial plastic degradation are also discussed.
\end{abstract}

Keywords: synthetic plastics, microbial degradation, symbionts, detection techniques, methods of acceleration, thermostable hydrolases

DOI: $10.1134 /$ S0026261721060084

Synthetic plastic materials are utilized in a great variety of human activity fields, and it would be difficult or even impossible to imagine the modern world without plastics. One of their key properties is high resistance to environmental factors, including biodegradation. However, it is the very same property that caused one of the central problems of the modern civilization, namely, the accumulation of enormous amounts of plastic waste on Earth.

Due to ease of production and widespread use of plastics, their global production is constantly increasing; as a consequence, this augments the level of plastic pollution on Earth (Geyer et al., 2017; Plakunov et al., 2020; Lau et al., 2020). A significant contribution to this process is made by growing use of disposable items. In 2015, annual production of plastic materials reached 350 million tons, as opposed to 2 million tons in 1950 (Geyer et al., 2017); in 2019, it amounted to 368 million tons (Plastics Europe, 2021). Altogether, from 1950 to 2015,8300 million tons of plastic and additives employed in their production were produced.

Assuming that the current trends of increasing plastic production are maintained, it is expected that 33 billion tons of plastic waste will have been generated by 2050; most of it will end up at landfill sites or simply remain in the environment: soil, air, and water systems, polluting lakes, rivers, seas, and oceans (Rochman et al., 2013). It is estimated that nearly 8 million tons of macroplastic and 1.5 million tons of primary microplastic waste are annually released into oceans (Jambeck et al., 2015; Boucher and Friot, 2017). If the current trends persist, the total amount of plastic in the ocean may increase by an order of magnitude by 2025 in comparison to 2010 (Jambeck et al., 2015). The proportion of microplastic entering terrestrial habitats from 2012 to 2017 exceeded manifold its release in oceans (Horton et al., 2017).

Apart from synthetic fibers obtained from polyester, polyamide, and acrylate polymers, the largest segment in the global plastic production belongs to polyethylenes (36\%), while polypropylene and polyvinyl chloride constitute 21 and $12 \%$, respectively; polyethylene terephthalate, polyurethane, and polystyrene make up equal proportions of $10 \%$ each (Geyer et al., 2017). At the same time, the share of packaging materials in the total plastic waste is constantly increasing (Geyer et al., 2017).

Plastic waste represents a serious environmental hazard, first of all because of physical deterioration of ecosystems (Sheavly and Register, 2007). Plastic pollution provokes a detrimental effect on animals and 
humans (Schmaltz et al., 2020). Sea animals get entangled in floating plastic (Gall and Thompson, 2015; Kühn et al., 2015; Lusher et al., 2018); plastic debris also facilitates the spread of invasive species (Kiessling et al., 2015) that impair the nutrition of marine animals by incorporating into trophic chains (Laist, 1987; de Stephanis et al., 2013; Gall and Thompson, 2015; Brandon et al., 2019). Microplastics may efficiently deliver toxic pollutants known as reproductive toxins or carcinogenic and mutagenic agents (Wright and Kelly, 2017; Schmaltz et al., 2020), either initially present in the material or adsorbed from the environment (Gallo et al., 2018). This poses a potential hazard for human health, since, according to various estimates, every year a person consumes 39000 to 52000 microplastic particles (Schmaltz et al., 2020).

The current levels of plastic waste production and distribution contribute considerably to aggravation of greenhouse effects. If the existing trends persist, by 2050 , plastics will be responsible for $15 \%$ (by carbon) of total greenhouse gas emission (Zheng and Suh, 2019).

Currently, plastic wastes can be disposed of by thermal degradation, stored at landfill sites, or left in the environment (Peng et al., 2018; Ru et al., 2020). Recycling may delay but not avoid the ultimate disposal of plastic wastes. In spite of the advent of new techniques, such as pyrolysis, which converts plastic wastes into fuel, thermal degradation of plastics is currently performed mainly by combustion, either with or without energy recovery (Lau et al., 2020; Ru et al., 2020).

Microorganisms exhibit considerable metabolic plasticity and are capable of degrading numerous chemical compounds, including certain plastics. Investigation of these microorganisms, their metabolism and enzymatic activity, as well as application of various approaches and techniques to accelerate the target processes, may become the basis for biotechnologies of plastic waste disposal that would help solve the ecological problems associated with plastic pollution.

This review discusses the diversity of microorganisms that degrade most widely used plastics, the enzyme systems they possess, and the possibilities of intensifying the crucially important process of plastic waste degradation.

\section{GENERAL CHARACTERISTICS OF PLASTIC MATERIALS}

Currently, $80 \%$ of commercial plastic materials are obtained based on thermosoftening polymers, socalled thermoplastics, which can undergo reversible transition from solid to viscous state under the increasing temperature. Approximately $10-15$ basic varieties of industrial polymers are used for production of more than 4000 brands of construction thermoplastics
(Mel'nikova, 2013). In our review, we will consider the properties of the top five types of thermoplastics accounting for a major share in the global production: polyethylene, polypropylene, polyvinyl chloride, polyethylene terephthalate, and polystyrene. Their principal characteristics are presented in Table 1.

Nearly $90 \%$ of total plastic production are materials based on polyolefins (polyethylenes and polypropylene), polystyrenes, and polyvinyl chlorides; they withstand constant external stress of up to $10-15 \mathrm{MPa}$ and temperatures of up to $80 \pm 20^{\circ} \mathrm{C}$. Materials based on PET, polyamides, polycarbonates, and polyformaldehydes constitute approximately $9 \%$ of the total production volume. They have higher mechanical and thermal resistance, withstanding tensile stress of up to $140 \pm 20 \mathrm{MPa}$ and temperatures of up to $150^{\circ} \mathrm{C}$ (Mel'nikova, 2013).

Polyethylene (PE) is composed of ethylene monomers. There are several PE types produced using different techniques: e.g., low-density polyethylene (LDPE), high-density polyethylene (HDPE), or ultrahigh-molecular weight polyethylene (UHMWPE). LDPE is characterized by strongly branched chains with a degree of polymerization of $\sim 50000$, density of $910-935 \mathrm{~kg} / \mathrm{m}^{3}$, and crystallinity of 50-60\%. HDPE is a dense polymer material of linear molecules with polymerization degree of up to 300000 , density of $930-970 \mathrm{~kg} / \mathrm{m}^{3}$, and crystallinity of $70-85 \%$ (Galygin et al., 2012). Differences in the properties of LDPE and HDPE are mainly due to the branching of their macromolecules: the higher the number of branching sites in the chain, the higher the elasticity and the lower the crystallinity of the polymer. Both LDPE and HDPE are in high demand and widely used in nearly all industrial, agricultural, and household markets, mainly for packaging of goods. The share of UHMWPE in the total production is very low, but it should be mentioned as a highly promising material with a growing field of applications. UHMWPE is obtained using metalloorganic catalysis; its molecular weight ranges from 1.5 to $8 \mathrm{MDa}$. It has extreme strength and high cold resistance and serves to manufacture high-strength technical products, such as armor. As a physiologically inert material, UHMWPE is used in endoprosthetics. Due to its extremely low friction coefficient, it is used to manufacture artificial ice (Zakharov et al., 2009; Kudryashova, 2020).

Polypropylene (PP) also belongs to polyolefins: linear hydrocarbons with the general formula $\mathrm{C}_{n} \mathrm{H}_{2 n}$. This is the high-molecular-weight product of stereospecific propylene polymerization by ZieglerNatta catalysts conducted at $80^{\circ} \mathrm{C}$ and low to medium pressure $(0.3-10 \mathrm{MPa})$. Industrial $\mathrm{PP}$ production employs petrochemical products, as well as natural hydrocarbon gases. The stereoisomeric composition of polymers can vary depending on the polymerization technique: isotactic and syndiotactic PP have regu- 


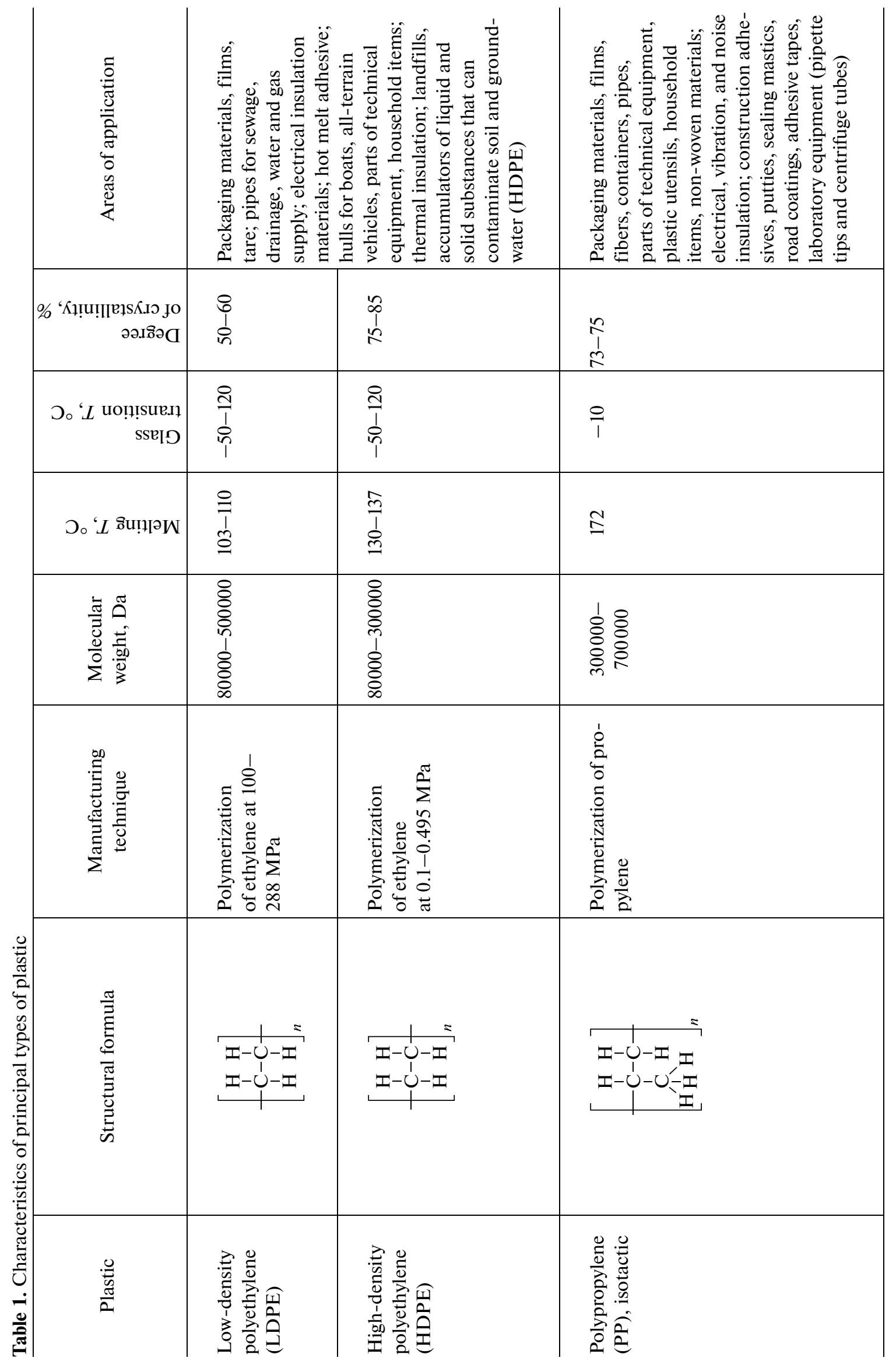


KOTOVA et al.

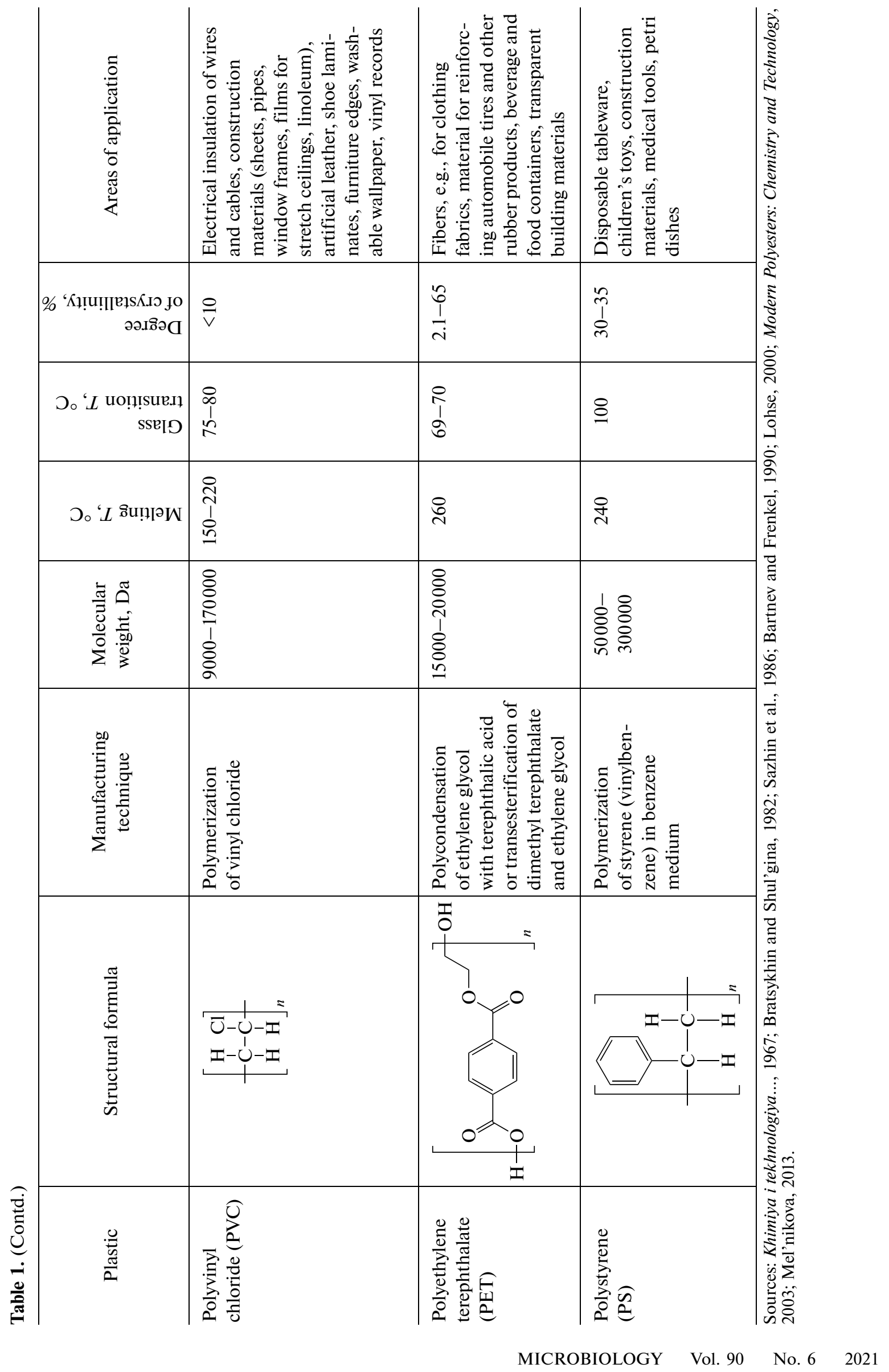


larly organized helical chains, while atactic PP features sterically irregular arrangement of methyl groups (Arutchelvi et al., 2008). PP is harder and less dense than PE; it is widely used for production of packaging materials, various consumer goods, nonwoven materials (including medical masks), and laboratory equipment (e.g., pipette tips and microcentrifuge tubes).

Polyvinyl chloride (PVC) is obtained by polymerization of vinyl chloride; it is characterized by high chemical resistance to alkali, most acids, and organic solvents. This polymer is composed of linear or weakly branched macromolecules. Its cold resistance is low $\left(-15^{\circ} \mathrm{C}\right)$. As a good dielectric, PVC is widely employed to manufacture cables and insulating materials; it is also used in the production of pipes, linoleum, window frames, stretch ceilings, and other goods. PVC is not used directly for manufacturing products; rather, they are made of PVC-based composite materials: vinyl plastic and flexible PVC (plasticate). Additionally, they contain heat stabilizers, lubricants, pigments or dyes, mineral fillers, and elastomers; plasticate also contains 30-90 mass parts of plasticizers (e.g., esters of phthalic, phosphoric, sebacic, or adipic acids). These materials are used to manufacture chemical equipment and communications, ventilation ducts, pipes, and construction elements. Transparent vinyl plastic serves to make bulk food containers, bottles, and other items. PVC plasticate is used to manufacture insulation and sheathing for electric wires and cables, hosepipes, linoleum and floor tiles, materials for wall cladding and furniture upholstery, or artificial leather. Transparent flexible PVC tubing is used in blood transfusion and life support systems in medical technology (Mel'nikova, 2013).

Polyethylene terephthalate (PET) is a polyester obtained by condensation of ethylene glycol with terephthalic acid or by transesterification of dimethylterephthalate and ethylene glycol. Its structure includes aliphatic and aromatic moieties. This intermittence of crystalline and amorphous fragments determines the principal properties of PET, such as hardness, impact resistance, and transparency, as well as extremely low gas permeability, water absorption, and plasticity in cold and hot states (Shevlik et al., 2016). PET is stable in the temperature range from -40 to $60^{\circ} \mathrm{C}$; it has a low friction coefficient and low hygroscopicity. Exposure to UV light can induce its degradation (Mel'nikova, 2013). Industrial production of PET is mainly based on petrochemical products. The high strength and durability of PET are due to a high content of aromatic terephthalate elements, which limit the mobility of polymer chains (Marten et al., 2005). PET is widely used for manufacturing containers for liquids and other consumer goods, fibers, and tissues (clothes).

Polystyrene (PS) is a synthetic polymer composed of monomers of styrene, an aromatic hydrocarbon; its chemical formula is $\left(\mathrm{C}_{8} \mathrm{H}_{8}\right)_{n}$; thus, the only elements it includes are carbon and hydrogen. Industrially produced PS has a degree of polymerization that ranges from 600 to 2500 . Phenyl groups prevent ordered arrangement of PS macromolecules and formation of crystalline structures. PS is a homopolymer with molecular weight of $100000-400000 \mathrm{~g} / \mathrm{mol}$. It is hard to depolymerize, since newly formed $\sigma$-bonds between carbon atoms are stronger than $\pi$-bonds of vinyl groups. The properties of PS depend on the character of phenyl group positioning relative to the zigzag carbon chain. PS is a rigid brittle amorphous polymer with a high level of optical light transmission and low mechanical strength. Is has low density $\left(1060 \mathrm{~kg} / \mathrm{m}^{3}\right)$, excellent dielectric properties, and good cold resistance (up to $-40^{\circ} \mathrm{C}$ ). Standard commercial PS is an atactic polymer with phenyl groups randomly arranged at both sides of the chain. This random arrangement prevents the formation of crystalline fragments, so the polymer is amorphous with the glass transition temperature $T_{\mathrm{g}}$ of $\sim 90^{\circ} \mathrm{C}$. PS is used for manufacturing disposable tableware, packaging, disposable laboratory equipment (e.g., petri dishes), medical instruments, and construction materials.

To sum up, all these types of plastic are widely employed in various areas of human activity. In spite of differences in structure and architecture, they all share a common quality: high resistance to environmental factors, including biological agents. Nevertheless, it has already been well established that a fairly large number of microbial species are capable of degrading plastics and utilizing their components as a source of carbon and energy. However, due to the extremely low rate of these processes, insolubility of plastics, their nonstandardized composition, and shape diversity, there is a need to employ various techniques to detect and quantitatively assess the microbial degradation of plastics.

\section{METHODS OF STUDYING MICROBIAL DEGRADATION OF PLASTICS}

All widely employed plastics discussed in this review are insoluble in water. Microbial interaction with the substrate occurs on the interphase boundary; accordingly, biodegradation is preceded by biofilm formation. The role of biofilms in plastic degradation was analyzed in detail in the recent review by Plakunov et al. (2020). A number of studies report on the composition of microbial biofilms that colonize the surface of various plastic materials exposed to diverse environments. For instance, Tourova et al. (2020) analyzed the biofilms that developed on PET specimens after 60 days of incubation in water of the Black Sea and in circulating water of a petrochemical plant and demonstrated that their composition was specific for the material. At the same time, evidence of changes on the PET surface was also reported (Laptev et al., 2019).

\section{MICROBIOLOGY Vol. $90 \quad$ No. $6 \quad 2021$}


Microbial degradation of plastics can be investigated using two fundamentally different approaches: (1) by testing pure cultures for their ability to degrade plastics; (2) by incubating plastic specimens in the presence of natural samples or directly in natural environments, such as soil, compost, landfill sites, water, or benthic sediments. The second approach is focused on natural selection of strains that possess the required activity.

It was proposed to consider the entire process of plastic biodegradation as divided in four stages (Sharma, 2018; Montazer et al., 2019):

(1) biodeterioration, which involves modification of polymer properties and facilitates its further degradation;

(2) biofragmentation, which results in hydrolysis and fragmentation of the carbon chains of the polymer, as well as release of intermediate products of degradation;

(3) bioassimilation of smaller hydrocarbon metabolite molecules by microbial cells and their incorporation into the microbial biomass;

(4) mineralization, which accompanies complete degradation of plastic to $\mathrm{CO}_{2}$ and water.

For each of these stages, a range of techniques can be used to document the changes that occur to the plastic. The principal methods used to detect microbial biodegradation of plastics are presented in Table 2 .

Primary information on the changes of the plastic surface can be obtained using various microscopic techniques. Most commonly, scanning electron microscopy (SEM) is used to study specimens from which the attached cells have been washed off in comparison to control specimens incubated in the absence of microorganisms. Atomic force microscopy (AFM) and other approaches can also be employed to investigate the polymer surface. Other methods can be used to detect changes in the structure of plastic: for instance, plastic specimens incubated in the presence of microbial cultures can be tested for their mechanical properties (tensile strength, extension at break, elastic constant, and yield point).

Biofragmentation can be registered based on the decrease in the mean molecular mass $\left(M_{n}\right)$ of polymeric carbon chains and widening of the molecular mass distribution as determined using gel permeation chromatography; intermediate products of plastic degradation can be detected using spectrometry, gas chromatography with mass spectrometry (GC-MS), high-performance liquid chromatography (HPLC), Fourier-transform infrared (FTIR) spectroscopy, and nuclear magnetic resonance (NMR) imaging. In particular, FTIR spectroscopy provides data on the content of various types of atomic bonds in the specimen, e.g., $\mathrm{C}-\mathrm{C}, \mathrm{C}-\mathrm{Cl}, \mathrm{C}-\mathrm{O}$, or $\mathrm{C}=\mathrm{O}$. The spectral changes may indicate oxidation, dechlorination (for PVC), or degradation of polymer chains. Thermo- gravimetric analysis is used to evaluate thermal stability of the plastic, which can be expected to decrease as a result of polymer chain shortening or break and increase following degradation or washing-out of plasticizers.

At this and subsequent stages, the microbial degradation of plastics can also be assessed by gravimetry as the most straightforward technique; for this purpose, the associated microbial cells must be thoroughly removed from plastic specimens.

Degradation of some plastics, e.g., PET, can be studied using various spectrophotometry methods to monitor the optical density of culture medium, either directly, based on production of light-absorbing compounds, or with addition of an indicator that reacts to changes in pH (Pirillo et al., 2021).

Bioassimilation of plastics can be estimated by the increase in microbial biomass growing in the presence of a plastic substrate, e.g., by amount of yielded protein produced in comparison to control.

Finally, mineralization of plastics is assessed based on the amount of released $\mathrm{CO}_{2}$ or, in the case of anaerobic processes, products of the terminal reductive reactions, such as $\mathrm{CH}_{4}, \mathrm{H}_{2} \mathrm{~S}$, or reduced nitrogen compounds.

As an auxiliary method, screening of microbial isolates can be performed on a solid medium containing dispersed fine particles (powder) of the polymer, where colonies of plastic-degrading microorganisms would be surrounded by a clear zone.

Finally, high accuracy can be achieved by using plastics labeled with ${ }^{14} \mathrm{C}$ isotope and determining accumulation of the label in the end products of degradation: ${ }^{14} \mathrm{CO}_{2}$ or ${ }^{14} \mathrm{CH}_{4}$ (Silelicki et al., 1978). Although this method is insensitive to the presence of biodegradable impurities or additives in the polymer, its application is limited due to the complexity of the assay and the high cost of radiolabeled polymers.

As a rule, to document changes within the polymer, each study should employ several techniques to register the changes in polymer structure, state of the microbial culture, and formation of intermediate or terminal products of plastic degradation (Müller, 2005; Lucas et al., 2008; Ru et al., 2020).

\section{EXAMPLES OF MICROBIAL DEGRADATION OF PLASTICS}

Although this kind of research is time- and laborconsuming and reliable results are difficult to obtain, a large number of experimental studies demonstrating microbial degradation of plastics have been performed in the two recent decades using the techniques described in the previous section. A few of them will be discussed below.

For instance, PE degradation by microorganisms has been described in numerous studies published in 
Table 2. Principal techniques used to detect microbial degradation of plastics

\begin{tabular}{|c|c|c|c|}
\hline Parameter analyzed & Method & $\begin{array}{c}\text { Signs of biodegradation } \\
\text { of plastic }\end{array}$ & References \\
\hline Features of plastic surfaces & $\begin{array}{l}\text { Scanning electron } \\
\text { microscopy (SEM), atomic } \\
\text { force microscopy (AFM) }\end{array}$ & $\begin{array}{l}\text { Changes in the structure } \\
\text { of the surface: formation } \\
\text { of microflaws, holes, uneven } \\
\text { relief }\end{array}$ & $\begin{array}{l}\text { Sarmah and Rout, 2018; } \\
\text { Muhonja et al., 2018; } \\
\text { Skariyachan et al., 2018; } \\
\text { Delacuvellerie et al., 2019; } \\
\text { Park and Kim, 2019, and } \\
\text { other }\end{array}$ \\
\hline $\begin{array}{l}\text { Tensile strength (TS) and } \\
\text { extension at break (EAB) }\end{array}$ & Tensiometry & $\begin{array}{l}\text { Decrease in TS and EAB } \\
\text { (in the course of LDPE } \\
\text { degradation) }\end{array}$ & Skariyachan et al., 2018 \\
\hline $\begin{array}{l}\text { Glass transition tempera- } \\
\text { ture }\end{array}$ & $\begin{array}{l}\text { Differential scanning } \\
\text { calorimetry (DSC) }\end{array}$ & $\begin{array}{l}\text { Decrease in the glass } \\
\text { transition temperature }\end{array}$ & $\begin{array}{l}\text { Lucas et al., 2008; Park and } \\
\text { Kim, } 2019\end{array}$ \\
\hline Degree of crystallinity & $\begin{array}{l}\text { Fourier-transform infrared } \\
\text { (FTIR) spectroscopy }\end{array}$ & $\begin{array}{l}\text { Increase in the degree } \\
\text { of crystallinity due } \\
\text { to preferential degradation } \\
\text { of amorphous PE }\end{array}$ & $\begin{array}{l}\text { Sen and Raut, 2015; Das and } \\
\text { Kumar, } 2015\end{array}$ \\
\hline Hydrophobicity & $\begin{array}{l}\text { Measuring the contact angle; } \\
\text { BATH test }\end{array}$ & $\begin{array}{l}\text { Decrease in the contact angle } \\
\text { (increased hydrophilicity) }\end{array}$ & $\begin{array}{l}\text { Koutny et al., 2006; Das and } \\
\text { Kumar, } 2015\end{array}$ \\
\hline Residual mass of polymer & Gravimetry (weighing) & $\begin{array}{l}\text { Decrease in the mass } \\
\text { of plastic }\end{array}$ & $\begin{array}{l}\text { Sarmah and Rout, 2018; } \\
\text { Skariyachan et al., 2018; } \\
\text { Mohan Rasu et al., 2018; } \\
\text { Delacuvellerie et al., 2019; } \\
\text { Park and Kim, } 2019\end{array}$ \\
\hline Chemical composition & FTIR spectroscopy & $\begin{array}{l}\text { Increase in the carbonyl } \\
\text { index; formation of interme- } \\
\text { diates with additional } \\
\text { functional groups } \\
\text { (carbonyl/carboxyl) and } \\
\text { alkanes; appearance of novel } \\
\text { peaks corresponding } \\
\text { to carbonyl and ether bonds }\end{array}$ & $\begin{array}{l}\text { Sarmah and Rout, 2018; } \\
\text { Muhonja et al., 2018; } \\
\text { Skariyachan et al., 2018; } \\
\text { Delacuvellerie et al., 2019; } \\
\text { Park and Kim, } 2019\end{array}$ \\
\hline Molecular weight & $\begin{array}{l}\text { Nuclear magnetic resonance } \\
\text { (NMR), gas chromatography/ } \\
\text { mass spectrometry (GC-MS), } \\
\text { gel permeation chromatography } \\
\text { (GPC) }\end{array}$ & $\begin{array}{l}\text { Decrease in the mean } \\
\text { molecular weight }\end{array}$ & $\begin{array}{l}\text { Yamada-Onodera et al., } \\
\text { 2001; Sarmah and Rout, } \\
\text { 2018; Muhonja et al., 2018; } \\
\text { Skariyachan et al., 2018; } \\
\text { Park and Kim, } 2019\end{array}$ \\
\hline Microbial biomass & $\begin{array}{l}\text { Analysis of protein (biomass) } \\
\text { yield }\end{array}$ & $\begin{array}{l}\text { Increased amounts } \\
\text { of microbial protein } \\
\text { in the presence of the poly- } \\
\text { mer }\end{array}$ & Sarmah and Rout, 2018 \\
\hline
\end{tabular}

the recent 20 years and currently represents a topical issue in the research on plastic degradation (Shah et al., 2008; Ammala et al., 2011; Sen and Raut, 2015; Harrison et al., 2018). It is well established that PE biodegradation under normal conditions is an extremely slow process. PE molecules with their simple linear structure are highly resistant to biodegrada- tion. The low rate of PE biodegradation is also due to the high hydrophobicity of the molecules composed only of $-\mathrm{CH}_{2}$ groups and to their high molecular weight (more than $30 \mathrm{kDa}$ ), which prevents their direct uptake by microbial cells (Orr et al., 2004; Sivan et al., 2006). For instance, in a microbial culture where PE was the sole energy source, fragments of 
smaller size were utilized more rapidly than larger ones (Kawai et al., 2004). It was also reported that a significant biodegradation level can be achieved in a reasonable time if the mean molecular weight of $\mathrm{PE}$ is less than 5000 Da (Reddy et al., 2009). LDPE chains with their branched structure are more susceptible to degradation, and tertiary carbon atoms at branching sites are more readily attacked. HDPE has a much higher molar weight, which probably impairs the access to the polymer chains for microorganisms and their enzymes (Sudhakar et al., 2008; Fontanella et al., 2010). It was shown that structural variations of PE polymers generated in the course of polymerization and subsequent processing, such as unsaturated double $\mathrm{C}=\mathrm{C}$ bonds, carbonyl groups, and hydroperoxide groups, are the first to be utilized by bacteria, promoting rapid microbial growth (Ojeda et al., 2011). While the microbial origin of PE biodeterioration and biofragmentation has been sufficiently well documented (Albertsson and Karlsson, 1990; Ammala et al., 2011), evidence of PE bioassimilation and complete mineralization is scarce (Yang et al., 2014; Sen and Raut, 2016; Montazer et al., 2019).

Table 3 lists examples of PE degradation studies reported in different publications. The considerable diversity of PE materials and culture conditions used makes it difficult to compare the results obtained in different biodegradation experiments. This fact emphasizes the need to develop standardized methods and protocols for systematic studies of plastics biodegradation, as it was proposed in the recent review by Montazer et al. (2020).

To date, little is known about the process of PP degradation. At any rate, it is obvious that the length of the molecules, their highly ordered structure, the lack of groups available for oxidation, and the presence of methyl side groups impair biodegradation of PP (Jeon and Kim, 2016). As a rule, PP specimens incubated with microbial cultures exhibit some decrease of plastic weight; however, the observed rates ranged from $0.43 \%$ in 12 months (Arkatkar et al., 2009) to $6.4 \%$ in 40 days (Auta et al., 2018) for pure PP exposed to bacterial cultures and from $1.4 \%$ in 3 months (Sheik et al., 2015) to $18 \%$ in 12 months for PP containing a catalyst together with cultures of micromycetes: Phanerochaete chrysosporium or Engyodontium album (Jeyakumar et al., 2013). Biodegradation of PP is assessed by formation of biofilms, by increase in the protein or ATP content in the culture in comparison to control without plastic addition, by decrease in the molecular weight of the polymer, by increase in the surface hydrophilicity, and by changes in the IR spectra.

Biodegradation of PVC waste is difficult to study because typical consumer goods made of this material contain large amounts of various additives, such as plasticizers, heat stabilizers, antipyrene, or biocides, which may constitute up to $50-75 \%$ of total weight. It is well known that many microorganisms can grow on media containing plasticizers as a sole source of carbon and energy (Berk et al., 1957; Booth et al., 1968; Webb et al., 2000; Nakamiya et al., 2005; Sabev et al., 2006; Das et al., 2012). Accordingly, a decrease in the weight of plastics exposed to microorganisms or changes in their physical properties, such as flexibility or tensile strength, may be due to diminishing amount of additives rather than to degradation of PVC chains (Luzia et al., 2020; Ru et al., 2020). This problem can be addressed by using pure PVC powder (Wu et al., 2017) or pure PVC plates obtained in the laboratory by dissolving commercial polymer in tetrahydrofurane (Kirbas et al., 1999; Ali et al., 2014; Khatoon et al., 2019), as well as by employing additional methods of analysis. Among them, the most commonly used ones are IR spectroscopy, thermogravimetric analysis, and gel permeation chromatography (Raddadi and Fava, 2019).

The high strength and durability of PET are due to the high content of aromatic terephthalate elements, which limits the mobility of the polymer chains (Marten et al., 2005) and makes PET highly resistant to microbial degradation (Andredy, 1994; Zheng et al., 2005; Müller, 2006; Tokiwa et al., 2009). The degree of crystallinity of this polymer, which usually exceeds 30-40\% (Liu et al., 2004; Lee et al., 2013), and its surface hydrophobicity are significant for PET biodegradability, because microbial enzymes attack mainly amorphous sites of the plastic, which are of key importance for primary adhesion of potential degraders (Urgun-Demirtas et al., 2007; Wang et al., 2016).

While PS is amorphous, its molecules are nonpolar and have high molecular weight, and the polymer itself is insoluble in water, which strongly protects PS from the effect of enzymes (Motta et al., 2009). Furthermore, phenyl side groups with their random spatial arrangement are highly resistant to biodegradation (Atlas and Barta, 1987). The available data on microbial degradation of PS are controversial. A number of researchers believe that PS is resistant to microorganisms. For instance, a PS film incubated for 8 months with pure cultures of Microbacterium sp. NA23, Paenibacillus urinalis NA26, Bacillus sp. NB6, and Pseudomonas aeruginosa NB26 isolated from soil was not affected by their activity (Atiq et al., 2010), and a PS sheet buried in soil for 32 years had no signs of degradation (Otake et al., 1995). Other authors underline that PS is degraded by microorganisms very slowly, because it comprises $75 \%$ of aromatic moieties and its molecular weight is very high. The hydrophobic nature of PS enhances its resistance to hydrolysis and affects the ability of microorganisms to adhere to the surface. The high molecular weight of PS and its poor solubility in water prevent it from being transported through the cell wall and the cytoplasmic membrane for further assimilation. Microbial exoenzymes cannot penetrate into the polymer and act on its surface only. Biodegradation of PS is most frequently studied using SEM and fluorescent microscopy (which enables 


\begin{tabular}{|c|c|c|c|c|c|c|c|c|c|c|c|c|c|c|c|c|c|c|c|c|}
\hline 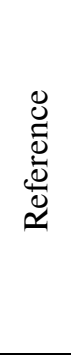 & 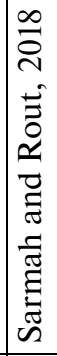 & 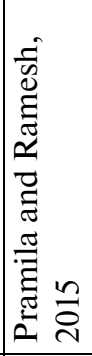 & 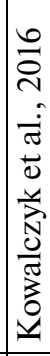 & 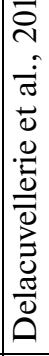 & 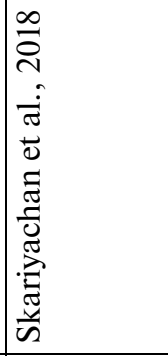 & 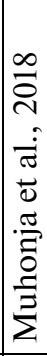 & 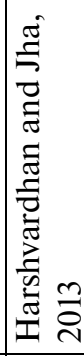 & 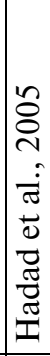 & 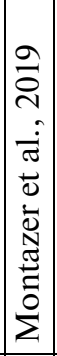 & 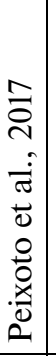 & 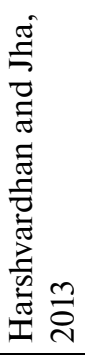 & 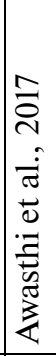 & 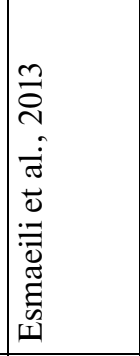 & 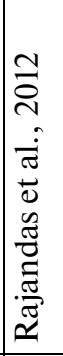 & 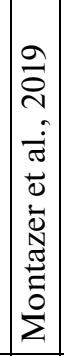 & 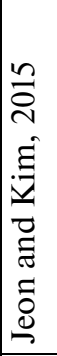 & 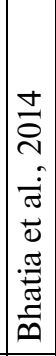 & 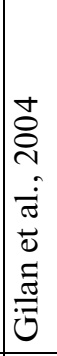 & 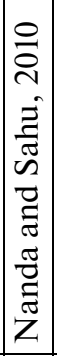 & 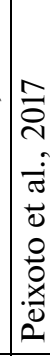 \\
\hline 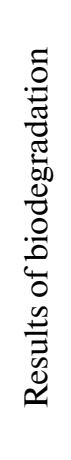 & 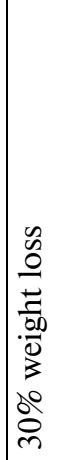 & 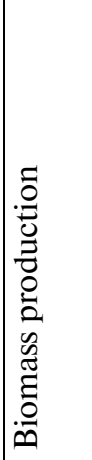 & 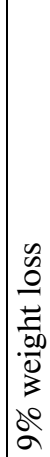 & $\frac{n}{0}$ & 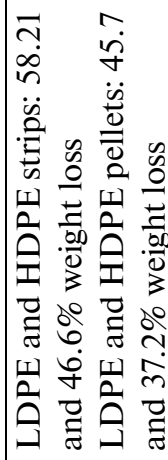 & 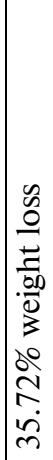 & 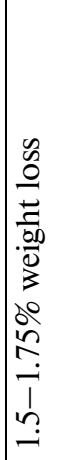 & 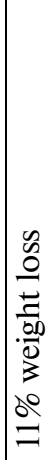 & 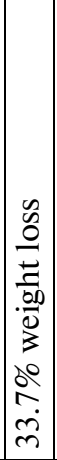 & 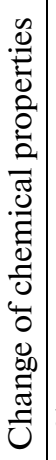 & 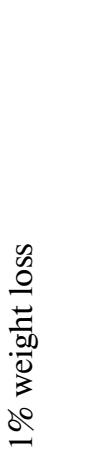 & 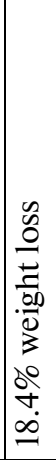 & 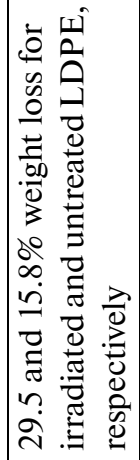 & 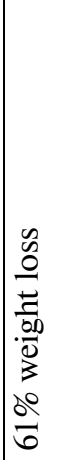 & 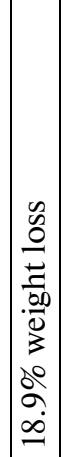 & 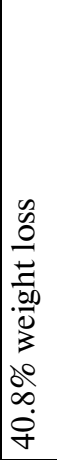 & 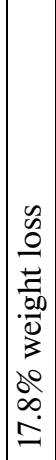 & 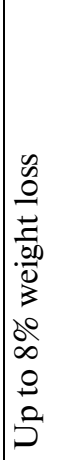 & 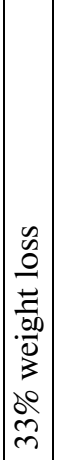 & 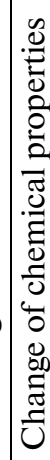 \\
\hline
\end{tabular}

\begin{tabular}{|c|c|c|c|c|c|c|c|c|c|c|c|c|c|c|c|c|c|c|c|c|}
\hline 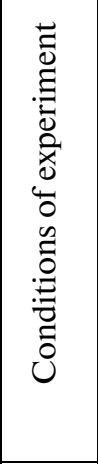 & 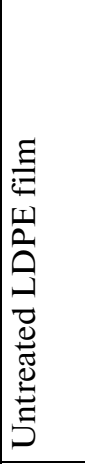 & 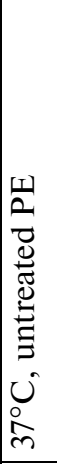 & 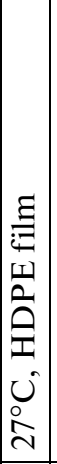 & 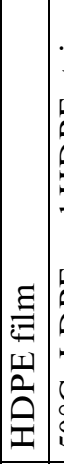 & 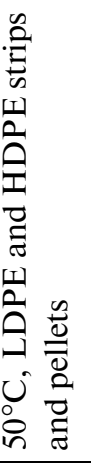 & 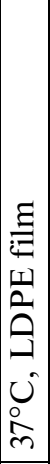 & 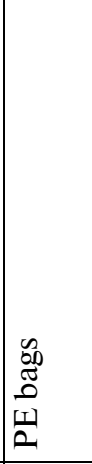 & 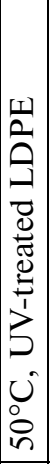 & 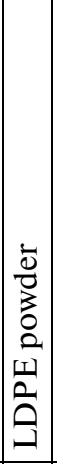 & 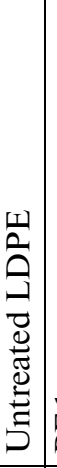 & 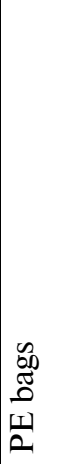 & 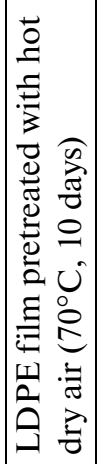 & 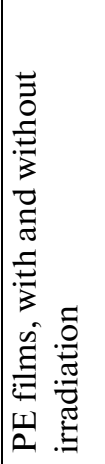 & 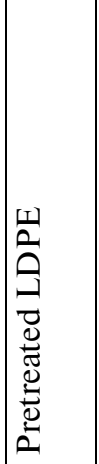 & 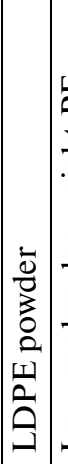 & 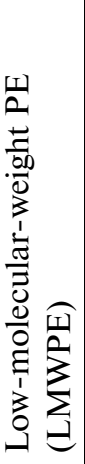 & 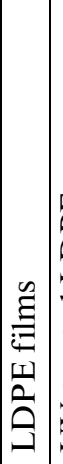 & 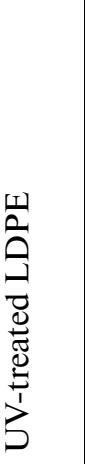 & 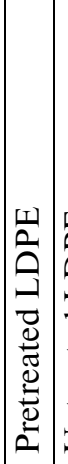 & 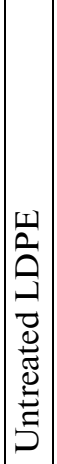 \\
\hline 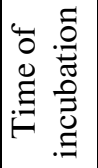 & 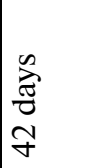 & 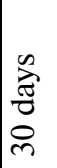 & $\mid \begin{array}{l}\text { 勇 } \\
\text { in } \\
\text { in }\end{array}$ & 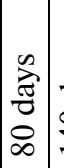 & 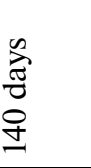 & 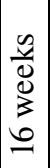 & 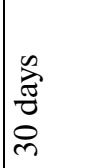 & 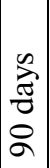 & 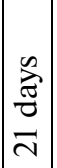 & 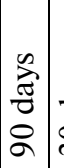 & 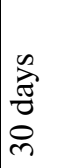 & 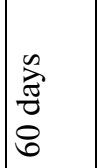 & 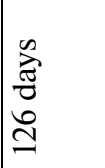 & $\begin{array}{l}\text { Ẽ } \\
\stackrel{\Xi}{\Xi} \\
0 \\
\Xi \\
\text { v }\end{array}$ & 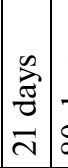 & $\begin{array}{l}\overbrace{\overparen{J}}^{\infty} \\
\infty \\
\infty\end{array}$ & 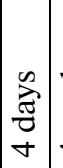 & 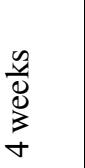 & 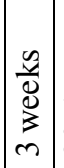 & 祘 \\
\hline $\begin{array}{l}0 \\
\stackrel{0}{\Xi} \\
\dot{0} \\
\tilde{n}\end{array}$ & 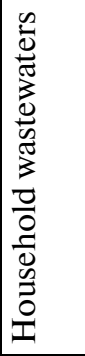 & 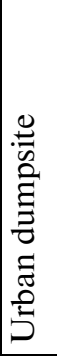 & 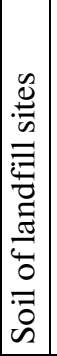 & 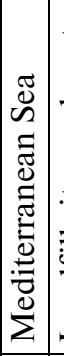 & 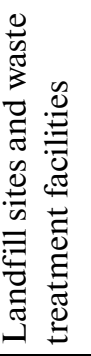 & 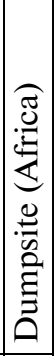 & 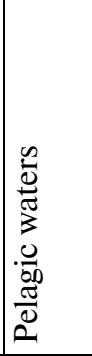 & $\sum_{\tilde{\omega}}^{N}$ & 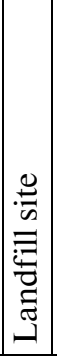 & $\mid \begin{array}{l}\overline{0} \\
0 \\
0 \\
. \\
0 \\
0 \\
0 \\
0 \\
3 \\
0 \\
0 \\
0 \\
0 \\
\frac{0}{2} \\
2\end{array}$ & 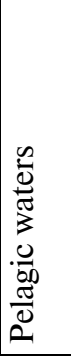 & 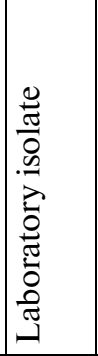 & 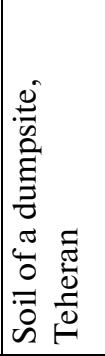 & 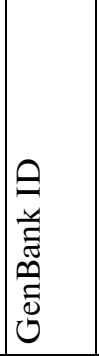 & 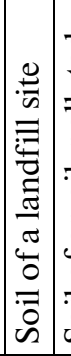 & 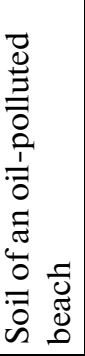 & 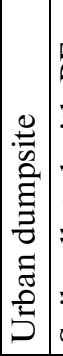 & 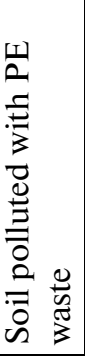 & 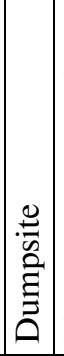 & 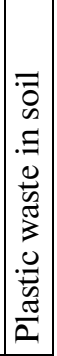 \\
\hline 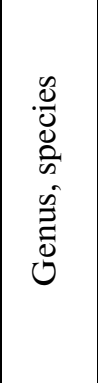 & 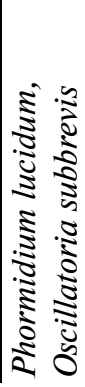 & 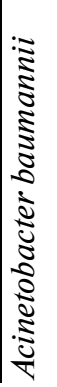 & 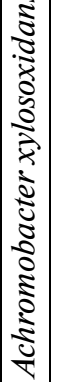 & 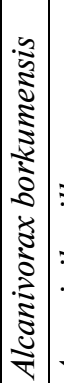 & 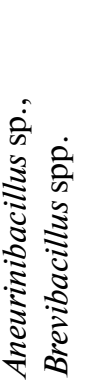 & 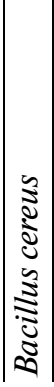 & 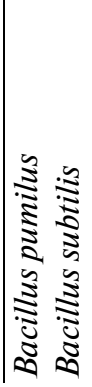 & 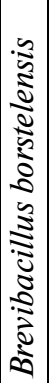 & 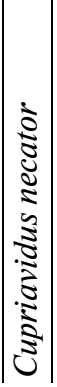 & 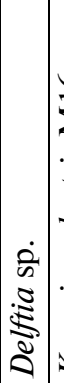 & 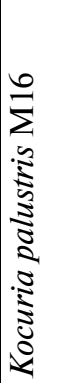 & 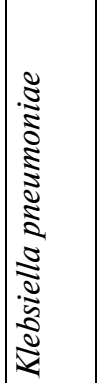 & 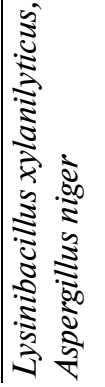 & 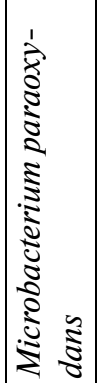 & 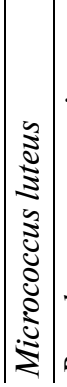 & 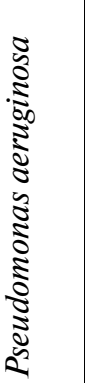 & 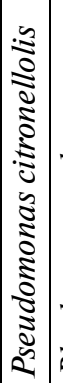 & 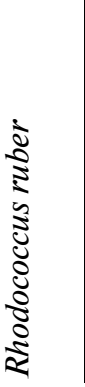 & 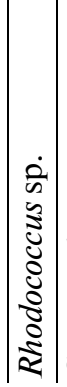 & 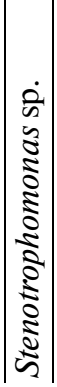 \\
\hline
\end{tabular}

MICROBIOLOGY Vol.90 $\quad$ No. $6 \quad 2021$ 
evaluating the microbial viability) to monitor visible changes of the plastic surface and color, as well as development of microbial fouling; further techniques include gravimetry, detection of intermediate products by spectrophotometry (for aromatic compounds), gas chromatography, HPLC, and FTIR spectroscopy, as well as quantitative assessment of gas uptake and release.

Thus, in spite of substantial technical difficulties, an assortment of methods developed specifically to address the problem of plastic decomposition serves to provide evidence on biodegradation of the most common types of plastics mediated by bacteria and fungi. Currently, there is still no information about involvement of archaea in these processes. Unfortunately, the diversity of substrates and specimen forms utilized (e.g., polymer film, powder, or beads) strongly impair the comparison of results across different studies. The nearest challenge for researchers is developing coordinated guidelines for plastic degradation studies, which could serve to resolve this issue.

\section{DIVERSITY OF FREE-LIVING MICROORGANISMS MEDIATING BIODEGRADATION OF PLASTICS}

Although biodegradation of plastics is a very slow process, this activity was described for many bacteria and micromycetes. Most frequently, microorganisms degrading PE and other types of plastics were isolated from soil, landfill sites, compost, seawater, and active sludge (Montazer et al., 2020). For instance, strains of Pseudomonas putida, Acinetobacter pittii, and Micrococcus luteus were shown to perform biofragmentation of preliminarily untreated LDPE and to utilize it as a source of carbon and energy (Montazer et al., 2019). The process was accompanied by production of alkanes and by accumulation of polyhydroxyalkanoates (biodegradable polymers) within the cells. Members of more than 20 bacterial genera were shown to participate in biodegradation of different PE types (Ghatge et al., 2020). Bacteria capable of degrading $\mathrm{PE}$ as well as the rates of the corresponding processes are presented in Table 3. Capacity of degrading PE was also detected in fungi of the genera Aspergillus, Cladosporium, Fusarium, Gliocladium, Mortierella, Mucor, Penicillium, and Zalerion (El-Shafei et al., 1998; Yamada-Onodera et al., 2001; Volke-Sepúlveda et al., 2002; Bonhomme et al., 2003; Manzur et al., 2004; Koutny et al., 2006; Hasan et al., 2007; Ahebnazar et al., 2010; Nowak et al., 2011; Pramila and Ramesh, 2011; Sheik et al., 2015; Paco et al., 2017). Fungi possess powerful enzyme systems and can survive under challenging environmental conditions at low levels of nutrient and water supply. Furthermore, they can widely spread their hyphae that penetrate the cracks and hollows on the plastic surface (Jeyakumar et al., 2013).
It was shown that bacteria of the genera Bacillus (Sudhakar et al., 2008; Abrusci et al., 2013), Rhodococcus (Bonhomme et al., 2003; Gilan et al., 2004; Fontanella et al., 2010), and Pseudomonas (Rajandas et al., 2012), as well as fungi of the genera Aspergillus and Fusarium (Hasan et al., 2007; Sahebnazar et al., 2010) can perform depolymerization of PE after various kinds of preliminary treatment, such as ultraviolet (UV) irradiation and/or thermal treatment, which make PE carbon chains more susceptible to biodegradation (Ammala et al., 2011).

The number of studies reporting successful microbial degradation of PP is very limited. For instance, it was shown that the mass of PP granules and films incubated for 140 days at $50^{\circ} \mathrm{C}$ with a consortium of bacteria isolated from wastewater treatment plants and landfills (Aneurinibacillus aneurinilyticus, Brevibacillus sp., B. agri, and B. brevi) decreased by 44 and $56 \%$, respectively (Skariyachan et al., 2018). The gravimetric data were confirmed by using FTIR spectroscopy, SEM, and some other techniques. For Bacillus cereus and Sporosarcina globispora, it was shown that their growth on a mineral medium containing PP as the sole source of carbon and energy was accompanied by a decrease of PP mass (Auta et al., 2017). However, most positive results on microbial degradation of PP were obtained using pretreatment of plastic, which will be discussed below.

The PVC-degrading ability of fungi and bacteria is difficult to study because of the presence of plasticizers, which may serve as true substrates for microorganisms cultivated on PVC (Kirbas et al., 1999; Webb et al., 2000; Peciulyte, 2002; Sabev et al., 2006). Experiments with pure PVC materials demonstrated the activity of Phanerocheate chrysosporium, Lentinus tigrinus, Aspergillus niger, and A. sydowii, as confirmed by the increase of fungal biomass, $\mathrm{CO}_{2}$ production, and SEM data (Ali et al., 2014). The authors observed the growth of the fungi on the plastic-supplemented medium, as well as the decrease in the mass of PVC free from plasticizers and additives (by $31 \%$ in 2 months), together with mineralization (by week 4, $\mathrm{CO}_{2}$ release constituted $13.74 \mathrm{mg} / \mathrm{L}$ ), and enhanced peroxidase activity accompanying the growth of biomass. A possible source of PVC-degrading fungi is soil polluted with this type of plastic. A recent study showed that isolation under these conditions led to selection of Mucor sp. and Penicillium sp. strains capable of growing on PVC-containing medium and causing partial degradation of plastic, as confirmed by IR spectrometry data (Pardo-Rodríguez and ZorroMateus, 2021).

Studies of PVC-degrading bacteria and fungi began at about the same time. In one of the first works, PVC substrate containing di-iso-octylsebacyanate as plasticizer was incubated under the laboratory conditions with the members of the genera Pseudomonas, Brevibacterium, and Achromobacter isolated from the sur- 
face of plastic items, which led to $20 \%$ weight loss and decrease of flexibility (Booth et al., 1968). However, in comparison to the number of studies on PVC-degrading fungi, there are considerably fewer reports about bacteria interacting with PVC, and many of them deal with utilization of plasticizers. The most interesting investigation on biodegradation of PVC films by cultures of Bacillus flexus and Pseudomonas citronellolis describes that 45-day-long incubation with both cultures led to fragmentation of PVC films, changed their IR-spectroscopy profiles, decreased their thermal stability, and diminished $M_{n}$ by $\sim 10 \%$; after 30 days of incubation, $P$. citronellosis caused $19 \%$ decrease in the gravimetric weight of PVC specimens (Giacomucci et al., 2019). The authors mentioned that the films used in their experiments contained up to $30 \%$ of various additives (citrates, adipates and polyadipates, epoxidized soybean oil, and $\mathrm{Zn}$ ), and the results obtained suggest the degradation of both PVC chains and additives. In another study, an artificial consortium of Pseudomonas otitidis, Bacillus aerius, B. cereus, and Acanthopleurobacter pedis was introduced into experimental soil samples with buried polymer films (Anwar et al., 2016). In comparison to control soil samples, incubation with the bacterial consortium resulted in significant damage of the plastic surface (SEM data) and changes of the IR and UV spectroscopy profiles, as well as in $78.5 \% M_{n}$ decrease (from 72.65 to $15.63 \mathrm{kDa}$ in 9 months, as opposed to $66.61 \mathrm{kDa}$ in control), suggesting degradation of polymer chains. These outstanding results are in strong contrast with the data obtained in other similar studies and require further exploration.

PET degradation is currently a subject of extensive research, and the most impressive results achieved by using PET-degrading enzymes will be discussed in a separate section below. Nevertheless, it is necessary to mention Ideonella sakaiensis, the best-known microorganism capable of efficient PET degradation (Yoshida et al., 2016). After 6 weeks of incubation at $30^{\circ} \mathrm{C}$, I. sakaiensis mediated a nearly complete degradation of PET films. However, to date, the principal source of PET-degrading enzymes are thermophilic actinobacteria isolated from compost, which grow at $50-60^{\circ} \mathrm{C}$ and promote degradation of polymer substrate, namely Thermomonospora fusca (Kleeberg et al., 1998), Thermobifida alba (Hu et al., 2010), Saccharomonospora viridis (Kawai et al., 2014), and Thermomonospora kurvata (Wei et al., 2014).

The body of data on microbial degradation of PS is fairly large, but they are rather controversial and difficult to compare because of variations in the polymer structure and diversity of techniques used to detect its degradation (Table 4). For instance, while most of Rhodococcus ruber cells attached to the PS substrate within a few hours, it was only after 8 weeks of cultivation that the polymer mass was observed to decrease by $0.8 \%$ (Mor and Sivan, 2008). Two bacterial strains iso- lated from a wetland in India, Exiguobacterium sibiricum and Exiguobacterium undae, were found to utilize solid transparent PS and PS beads as a source of carbon and energy (Chauhan et al., 2018). Using AFM, it was shown that the substrate surface became rougher, which decreased its hydrophobicity. FTIR spectroscopy revealed that oxidized groups appeared in the molecules, while gravimetry confirmed PS mass decrease by $0.4 \%$ in 30 days. At the same time, the strain of Bacillus paralicheniformis isolated from the Arabian Sea was able to degrade $34 \%$ of PS film mass in 60 days (Kumar et al., 2021). For fungi of the genus Curvularia, it was shown that their hyphae adhered to the surface of atactic PS and penetrated through it; the observed PS mass loss was $2-5 \%$ in $2-3$ months (Motta et al., 2009). Incubation of Enterobacter sp., Citrobacter sedlakii, Alcaligenes sp., and Brevundimonas diminuta in media containing PS as the sole source of carbon and energy led to $12 \%$ substrate depletion per month. It was found that brown rot fungi Gloeophyllum striatum and Gloeophyllum trabeum can attack PS via the Fenton reaction involving hydroquinone; after 20 days of incubation, significant PS depolymerization was observed, and the molecular weight decreased by nearly 50\% (Krueger et al., 2015). The fact of lignopolystyrene degradation by white rot fungi Pleurotus ostreatus, Phanerochaete chrysosporium, and Trametes versicolor was reported nearly 30 years ago (Milstein et al., 1992). After 8 weeks of incubation with Cephalosporium sp. and Mucor sp. cultures, the mass of PS decreased by $2.17 \pm 0.16$ and $1.81 \pm 0.13 \%$, respectively; the observed changes in the surface (from smooth to rough), decreased medium $\mathrm{pH}$, appearance of metabolic intermediates, and decreased molecular weight additionally confirmed PS degradation (Chaudhary et al., 2019).

Microbial degradation of PS was studied not only for pure cultures but also for natural microbial associations. The presence of PS promoted the succession of microorganisms in the community of active sludge under aerobic and anaerobic conditions (Wei et al., 2020). Biofilms formed by active sludge on PS cubes were growing during incubation from weeks 1 to 9 . SEM and X-ray spectroscopy revealed changes in the structure of PS, while FTIR spectroscopy indicated the appearance of intermediates of unknown composition. In experiments with addition of two types of ${ }^{14} \mathrm{C}$-labeled PS ( $\alpha$ - and $\beta-{ }^{14} \mathrm{C}$ ) to soil and active wastewater sludge, only $0.01 \%$ of PS was oxidized to ${ }^{14} \mathrm{CO}_{2}$ after 8 weeks, and the total conversion level after 75 days was $0.7 \%$ (Giullet et al., 1974). Low degrading activity on ${ }^{14} \mathrm{C}$-PS was also reported for mixed cultures of 17 lignin-degrading fungal strains, as well as for the microbial communities of sludge, various soils, manure, and landfill sites (from 0.04 to $3.0 \%$ in 16 weeks; Sielicki et al., 1978; Kaplan et al., 1979). Significantly higher rates of PS foam degradation were observed for the samples from the landfill site in 


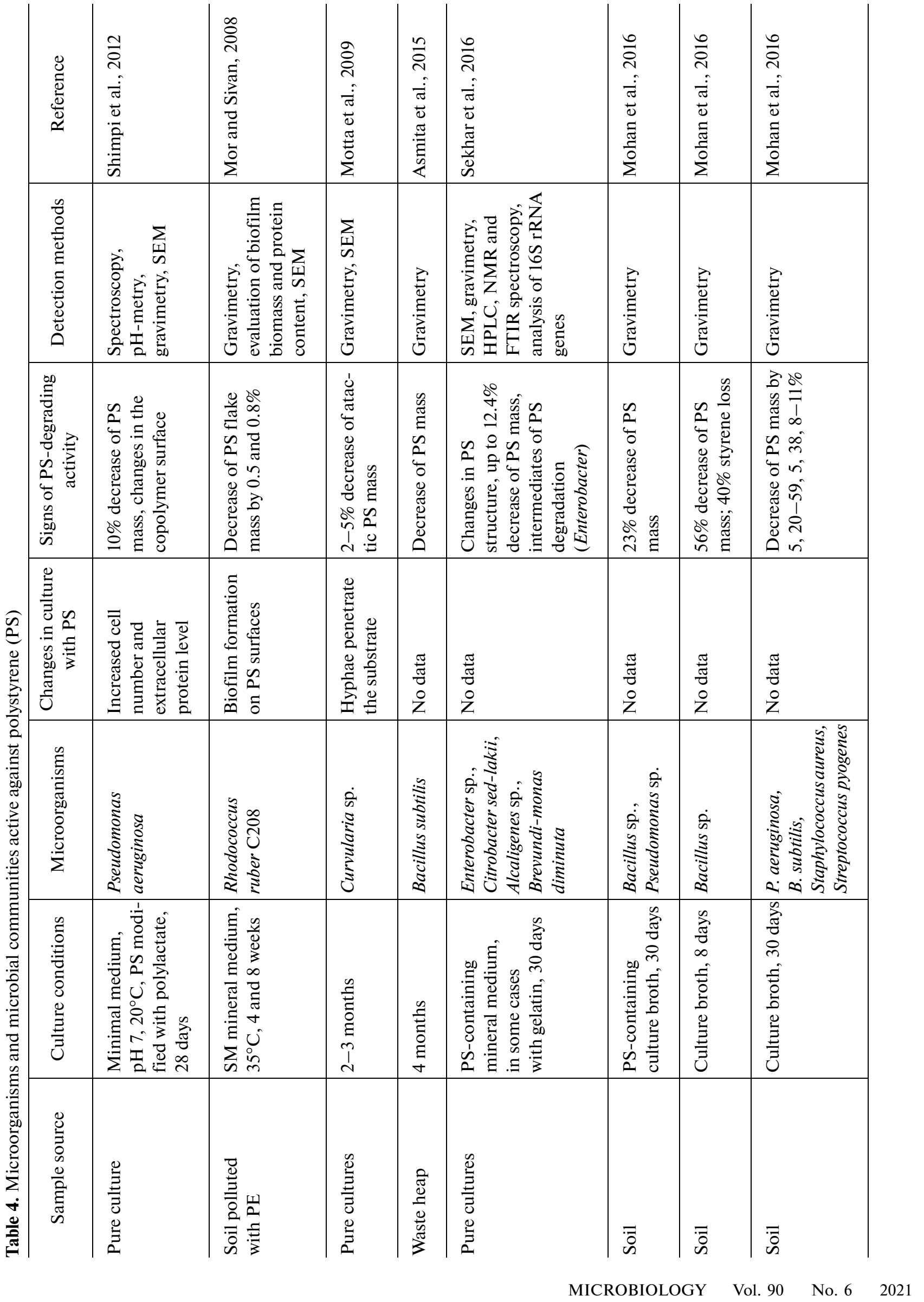




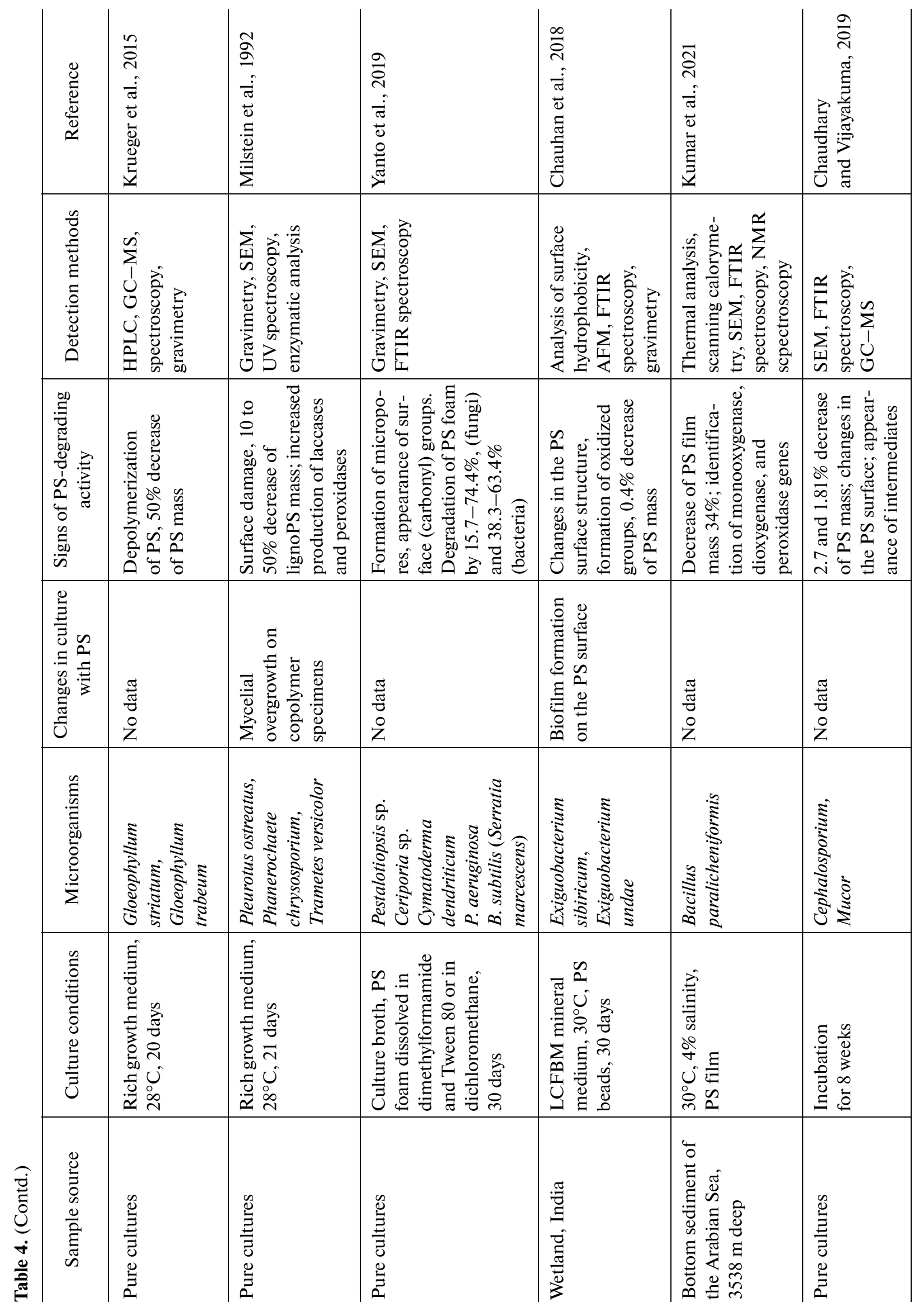

$\begin{array}{llll}\text { MICROBIOLOGY Vol.90 No. } 6 & 2021\end{array}$ 
KOTOVA et al.

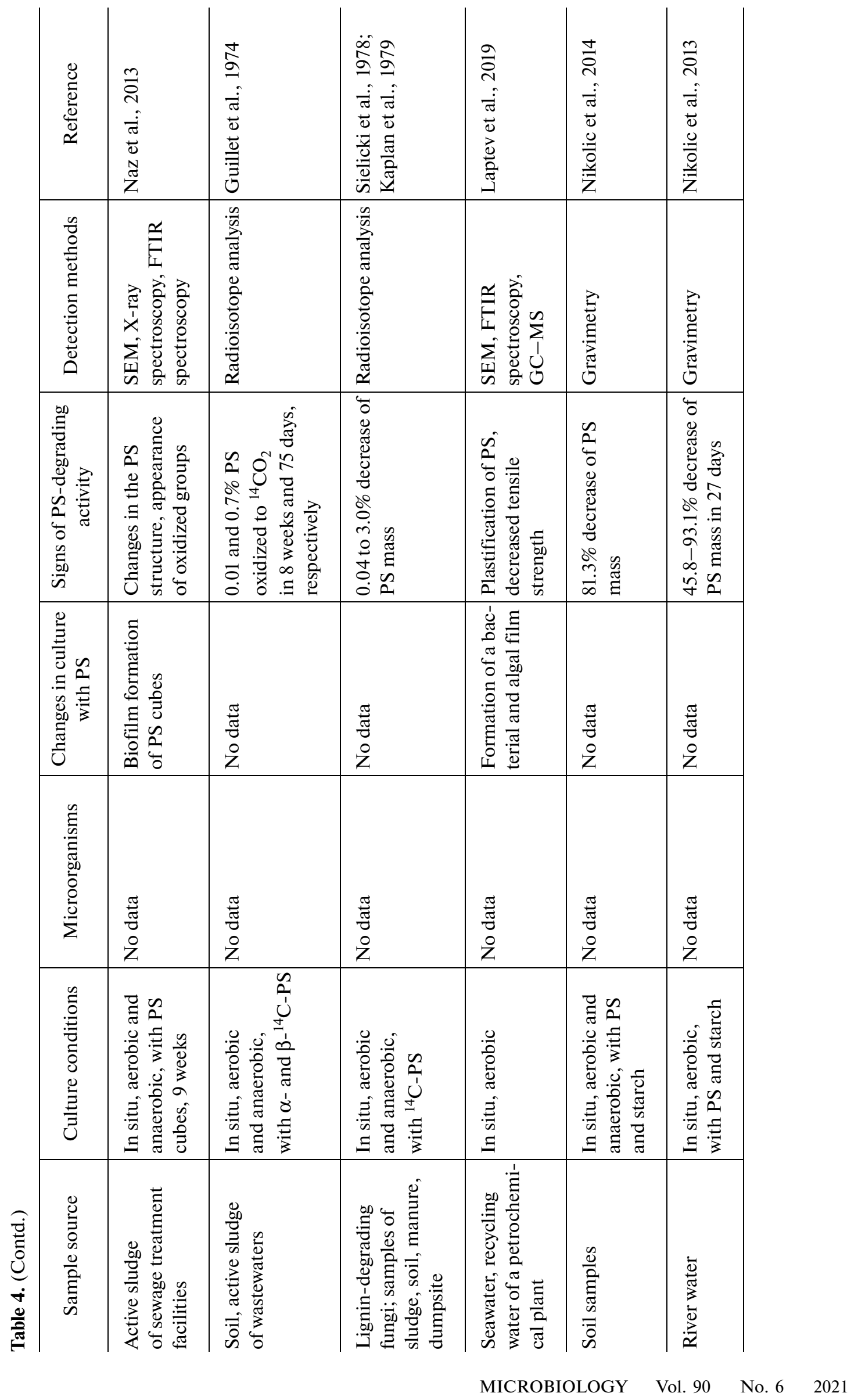


Sarimukti (Indonesia): the mass of PS foam decreased by $18.23 \%$ after 7 weeks of incubation (Hidayat et al., 2020). SEM showed the appearance of pores on the plastic surface, while FTIR spectroscopy confirmed the formation of simpler functional groups in the molecules and appearance of $\mathrm{C}-\mathrm{O}$ groups. Presumably, degradation of PS foam was mediated by bacteria of the genera Pseudomonas and Bacillus.

\section{PLASTIC-DEGRADING MICROBIAL SYMBIONTS OF INVERTEBRATES}

It is known that some invertebrates can consume plastics, and this phenomenon, and specifically the gut microbiomes of these organisms, have recently started attracting rapidly growing attention. For the first time, the fact that some insects can make holes in PE film was reported in 2007 (Riudavets et al., 2007). Subsequently, strains of Enterobacter asburiae and Bacillus sp. isolated from the gut of Plodia interpunctella (Indianmeal moth) were shown to utilize PE film by 6 and $10 \%$ in 60 days, respectively, while the molecular weight of the remaining PE decreased (Yang et al., 2014).

Larvae of greater wax moth Galleria mellonella were found to rapidly degrade PE (13\% weight decrease in $14 \mathrm{~h}$ ) with production of ethylene glycol (as shown using FTIR spectroscopy). A strain of Enterobacter sp. isolated from their gut caused changes of the physical and chemical properties of PE films after 31 days of incubation, as observed using FTIR spectroscopy, GC-MS, SEM, and AFM (Ren et al., 2019). Larvae of $G$. mellonella also exhibited capacity of degrading PS, as indicated by a significant decrease of plastic substrate mass, appearance of $\mathrm{C}=\mathrm{O}$ and $\mathrm{C}-$ $\mathrm{O}$ groups in the molecules, and production of longchain fatty acids (Lou et al., 2020). A study of their gut microbiome composition showed that consumption of plastic was associated with predominance of Bacillus and Serratia species. Moreover, individual isolates were less efficient in degrading PS than the gut microbial community.

Biodegradation of PE and other plastics was recently described for larvae of various insects, such as mealworm beetle Tenebrio molitor (Billen et al., 2020), dark mealworm beetle Tenebrio obscurus (Brandon et al., 2018; Peng et al., 2019), giant mealworm beetle Zophobas atratus (Peng et al., 2020), and lesser wax moth Achroia grisella (Kundungal et al., 2019), as well as for the land snail Achatina fulica (Song et al., 2020). The strains of Acinetobacter sp. and Bacillus sp. isolated from the gut of T. molitor larvae were capable of growing on LDPE only in a coculture, diminishing LDPE mass by $18 \%$ in 30 days of cultivation (Yin et al., 2020).

Interesting results were obtained for larvae of mealworm beetle T. molitor growing on a PVC powder (Peng et al., 2020). Polymer chains were partially degraded to small chloroorganic compounds, and $M_{n}$ decreased by $33.4-36.4 \%$. However, complete mineralization of the polymer substrate was very slow. Tenebrio molitor also exhibited similar activity against PE and PS substrates (Wu et al., 2019). Importantly, addition of antibiotics significantly inhibited the biodegradation, demonstrating the crucial role of the gut microbiome in this process. Analysis of variable fragments of the 16S rRNA genes of the gut microbial community showed that feeding on PVC promoted the predominance of Streptococcaceae (primarily, the genus Lactococcus), Spiroplasmataceae, Enterobacteriaceae, and Clostridiaceae families, which were significantly less abundant on the standard bran feed.

PS-degrading ability was studied for larvae of two mealworm species, T. molitor and T. obscurus (Yang et al., 2015a, 2015b; Peng et al., 2019). Radioisotope analysis showed that, in $24 \mathrm{~h}, 47.7 \%$ of ${ }^{13} \mathrm{C}$-labeled PS foam was metabolized to $\mathrm{CO}_{2}, 49.2 \%$ was excreted, and a minor part was incorporated into lipids. GS-MS analysis recorded the following intermediates of PF degradation: pentanone, 4-hydroxy-4methylbenzene, 2,2-dimethyl-1,3-dioxolan-4-methanol, oxalate, butyl-6-ethyloct-3-yl-ester, phenol, 2,4-bis(1,1-dimethyletyl), 1,2-benzenedicarboxylate, butyl-2-methylpropyl ester. Pronounced succession was observed in the gut microbial community of larvae feeding on PS foam: the initially predominant lactoand enterobacteria were replaced by streptococci, and finally by spiroplasmas and enterococci. The fact that suppression of gut microbiota with antibiotics resulted in nearly complete arrest of plastic utilization proves its key role in PS degradation. Thirty bacterial isolates were obtained from the larvae gut and identified; subsequently, they were incubated as pure cultures in the presence of PS for 28 days. Strains of Bacillus cereus, Enterobacter hormaechei, Enterococcus gallinarum, E. faecalis, Chryseobacterium sp., and Exiguobacterium sp. exhibited a significant increase in abundance; after the cultivation of Exiguobacterium sp. on PS for 60 days, gas chromatography revealed numerous peaks of intermediate compounds in the culture medium, and the plastic mass decreased by $\sim 7.5 \%$.

Larvae of Zophobas atratus consumed $0.58 \mathrm{~g}$ PS per day: 4 times more than larvae of T. molitor. Various methods of analysis demonstrated PS depolymerization and formation of low-molecular-weight intermediates in their gut, while $36.7 \%$ of carbon present in PS foam were mineralized to $\mathrm{CO}_{2}$ within 16 days (Yang et al., 2020). A strain of Pseudomonas aeruginosa isolated from the gut of $Z$. atratus larvae was capable of degrading PS, and it was found that expression of its serine hydrolase was upregulated in the course of PS degradation (Kim et al., 2020). Larvae of Plesiophthalmus davidis beetle consumed $34.27 \pm 4.04 \mathrm{mg}$ PS foam per individual in 14 days and survived on the feed of plastic only. When enrichment cultures of their gut microbiota were incubated for 20 days with PS, bio- 
film formation and morphological modifications (formation of cavities) were observed on the plastic surface. FTIR spectroscopy showed that $\mathrm{C}-\mathrm{O}$ bonds appeared in the molecules. Analysis of the gut microbial community revealed the presence of Serratia marcescens; in larvae fed with PS for 2 weeks, the abundance of these bacteria increased sixfold (Woo et al., 2020).

A recent study investigated the ability of common land snail, Achatina fulica, to utilize PS foam (Song et al., 2020). PS was consumed at the rate of $18.5 \pm$ $2.9 \mathrm{mg}$ per snail in 4 weeks and excreted as microplastic with the mean mass loss of $30.7 \%$. Different methods of analysis revealed changes in the molecular weight of residual PS and appearance of oxidized groups in PS molecules. Analysis of the composition of the microbial community by high-throughput sequencing of $16 \mathrm{~S}$ rRNA genes showed a significant increase in the relative abundance of bacteria of the families Enterobacteriaceae, Sphingobacteriaceae, and Aeromonadaceae, indicating their possible involvement in biodegradation.

\section{MECHANISMS OF MICROBIAL DEGRADATION OF PLASTICS}

PE and other plastics that contain only carbon-carbon bonds in the main chain are highly resistant to various environmental factors, including microbial activity (Wei and Zimmermann, 2017a); nevertheless, microorganisms possess a range of mechanisms that mediate degradation of plastics (Sheel and Pant, 2018). As a rule, microbial biodegradation of PE involves biofragmentation of the polymer by microbial enzymes with subsequent assimilation of the resulting small fragments with molar weights of less than $500 \mathrm{~g} / \mathrm{mol}$ (Bonhomme et al., 2003; Montazer et al., 2019).

To date, two groups of enzymes are known to participate in PE degradation, and both of them are also involved in degradation of two other types of resistant polymers: hydrocarbons and lignin. The first group includes alkane hydroxylases (Yoon et al., 2012; Jeon and Kim, 2015; Gravouil et al., 2017) and monooxygenases (Jeon and Kim, 2015; Moreno and Rojo, 2019), whereas the second one includes laccases (Santo et al., 2013; Sheel and Pant, 2018) and manganese peroxidase (Iiyoshi et al., 1998; Mukherjee and Kundu, 2014).

Alkane hydroxylases (EC 1.14.15.3) are the key enzymes mediating aerobic alkane degradation by bacteria (Monahan et al., 2020). The initial stage involves hydroxylation of $\mathrm{C}-\mathrm{C}$ bonds with formation of primary or secondary alcohols, which are next oxidized to aldehydes and ketones, and finally, to carboxylic acids. Carboxylated n-alkanes are similar to fatty acids, which can be catabolized by bacteria via the $\beta$-oxidation system. Transcriptome analysis showed that, in the presence of PE, Rhodococcus ruber expressed enzymes of alkane degradation and of the pathway of fatty acid $\beta$-oxidation (Gravouil et al., 2017). Recombinant $E$. coli cells expressing the complete alkane hydroxylase system from Pseudomonas aeruginosa isolated from oil-polluted beach soil mediated mineralization of $19.3 \%$ of low-molecular weight polyethylene (LMWPE) to $\mathrm{CO}_{2}$ in 80 days (Yoon et al., 2012). Many PE-degrading microorganisms were also shown to be capable of utilizing linear n-alkanes, e.g., paraffin $\left(\mathrm{C}_{44} \mathrm{H}_{90}, M_{\mathrm{w}}=618\right)$. It was found that decomposition of linear paraffin molecules can be mediated by several microorganisms during 20 days (Haines and Alexander, 1975). However, no information was reported on $\mathrm{C}-\mathrm{C}$ bond breaking in the main chain of PE polymers, as well as on the formation of hydrolysis products from long-chain carboxylic acids (Eubeler et al., 2010; Yoon et al., 2012; Gewert, 2015; Jeon and Kim, 2015).

Enzymes that mediate degradation of lignin are manganese peroxidase (EC 1.11.1.13), lignin peroxidases (EC 1.11.1.14), and laccases (EC 1.10.3.2); they were also shown to participate in PE degradation (Restrepo-Florez et al., 2014; Krueger et al., 2015). Exposure to extracellular copper-dependent laccase from Rhodococcus ruber caused a decrease of the average molecular weight and $M_{n}$ of UV-irradiated PE and increased the content of carbonyl groups in the polymer (Santo et al., 2013). Another enzyme involved in biodegradation of synthetic plastics, including PE, is manganese peroxidase (EC 1.11.1.13). It was shown that lignin-degrading fungi Phanerochaete chrysosporium, Trametes versicolor and strain IZU-154, as well as partially purified manganese peroxidase from P. chrysosporium, mediated PE degradation, and this process was stimulated by manganese ions (Iiyoshi et al., 1998). This enzyme was also demonstrated to mediate biodegradation of UV-irradiated PE (Mukherjee and Kundu, 2014). Certain data suggest that bacteria also possess similar mechanisms. For instance, synthesis of laccase and manganese peroxidase was stimulated in Bacillus cereus cells incubated with PE pretreated by UV irradiation (Sowmya et al., 2014). It was also found that lignin peroxidase of Streptomyces sp. induced degradation of PE after a heat treatment at $70^{\circ} \mathrm{C}$ (Pometto et al., 1992).

These and some other experimental data indicate that the enzymes listed above are involved in PE degradation. However, it should be kept in mind that, in most of these studies, plastic substrates were pretreated with UV radiation or heat, which made them more sensitive to enzyme activity.

There is currently no information available on the mechanisms of PP degradation. Data on PVC degradation mechanisms are also very scarce; however, it was shown that PVC degradation by $P$. chrysosporium is based on peroxidase activity (Khatoon et al., 2019). Furthermore, the observed damage to the plastic sur- 
face (SEM data) and changes in IR spectroscopy profiles were significantly more pronounced in PVC treated with purified peroxidase from $P$. chrysosporium than in plastic incubated in the presence of fungal culture only.

Mechanisms of PET degradation are subject of extensive research. Its biodegradation occurs by limited enzymatic hydrolysis of the ester bonds in the polymer backbone. Bacterial and fungal enzymes hydrolyze ester bonds in PET to produce terephthalate and ethylene glycol. Intermediate products of enzymatic hydrolysis are also mono-(2-hydroxyethyl) terephthalate (MHET) and bis-(2-hydroxyethyl) terephthalate (BHET) (Vertommen et al., 2005; Ronkvist et al., 2009), which can also be degraded by esterases to terephthalate and ethylene glycol (Austin et al., 2018; Maurya et al., 2020). At the same time, activity of PET hydrolases is inhibited by the MHET and BHET intermediates, as shown for polyester hydrolase TfCut 2 from Thermobifida fusca (Barth et al., 2015a).

The principal groups of PET-hydrolyzing enzymes are hydrolases, cutinases, cutinase-like PETase from Ideonella sakaiensis, as well as esterases and lipases produced by various fungi and bacteria (Table 5).

Cutinases (EC 3.1.1.74) have a broad substrate specificity and exhibit hydrolytic activity both towards insoluble triglycerides (typical substrates of lipases) and towards soluble esters (substrates of esterases) (Taniguchi, 2019). The list of known producers of PET-hydrolyzing cutinases includes strains of Fusarium solani, Thermobifida fusca, Thermobifida cellulolysitica, Humicola insolens, and Pseudomonas mendocina. Cutinase-mediated hydrolysis of PET is classified as so-called surface erosion of synthetic polymers (Zhang et al., 2004; Wei et al., 2014). In contrast to other enzymes that degrade biopolymers, e.g., cellulose or polyhydroxyalkanoates, cutinases lack specific binding domains responsible for adsorption to substrate (Chen et al., 2013; Wei et al., 2014). Their binding to the PET surface is determined by hydrophobic interactions with the residues located in immediate vicinity of the catalytic center of the enzyme, as it was shown for the cutinases of Thermobifida (Herrero Acero et al., 2011). The authors showed that it was the difference in electrostatic and hydrophobic properties of cutinases from $T$. cellulolysitica and $T$. fusca that determined the difference in their hydrolytic activity, which resulted in high yields of hydrolysis products in T. fusca. Cutinases are more active in biodegradation of PET; many of them are thermostable enzymes that can induce a considerable decrease of amorphous PET film mass (Wei et al., 2016). Cutinases from the fungus Fusarium solani and the bacterium Pseudomonas mendocina are active at $50^{\circ} \mathrm{C}$, and cutinase from the fungus Humilica insolens is stable in the temperature range of $70-80^{\circ} \mathrm{C}$; however, in experiments using PET with 7\% crystallinity, their activity was 10 times higher than with plastic with $35 \%$ crystallinity (Ronkvist et al., 2009).

According to sequencing data, PETase (PET hydrolase; EC 3.1.1.101) from Ideonella sakaiensis 201F6 (Yoshida et al., 2016) is similar to cutinases but has a wider active center with additional disulfide bridges (Kawai et al., 2020). This enzyme exhibits the highest hydrolytic activity towards low-crystallinity PET at ambient temperatures but, in contrast to other cutinases, it has low thermostability.

Enzymatic activity of esterases (EC 3.1) takes place on the interface between a water medium and a substrate insoluble in water. Experiments with esterase from Clostridium botulinum showed that PET-hydrolyzing activity of these anaerobic bacteria crucially depended on its zinc-binding domain, which distinguishes this enzyme from cutinases of aerobic microorganisms (Biundo et al., 2018; Kawai et al., 2019). Genetically engineered $C$. botulinum cells with certain mutations introduced into this esterase site exhibited facilitated binding to PET and enhanced hydrolytic activity (Biundo et al., 2016). Ester substrates of esterases usually have a shorter aliphatic chain than those hydrolyzed by lipases (Freddi et al., 2011). Therefore, only a limited number of esterases can participate in PET hydrolysis, e.g., $p$-nitrobenzylesterase isolated from Bacillus subtilis (BsEstB) (Ribitsch et al., 2011). In comparison to cutinases and lipases, esterases generally have a lower capacity of surface hydrolysis of polyesters; nevertheless, the PET-hydrolyzing activity of esterase from Thermobifida Thh_Est is comparable to activity of cutinases of the same genus (Ribitsch et al., 2012).

Lipases (EC 3.1.1.3) exhibit low PET-degrading activity because of limited substrate accessibility (Zimmermann and Billig, 2011). Data on PET degradation were reported for lipases from yeast Candida cylindracea, filamentous fungus Aspergillus oryzae, and bacteria Pseudomonas sp. (Wang et al., 2008; Ma et al., 2012; Maurya et al., 2020).

Polyesterase isolated from Penicillium citrinum was shown to mediate partial degradation of PET and a model substrate bis-(benzoyloxyethyl) terephthalate (3PET) with release of MHET and BHET as the cleavage products; however, the amounts of terephthalic acid were low (Liebminger et al., 2007). Among the enzymes known for their PET-hydrolyzing activity, it is worth mentioning recombinant thermostable polyesterase from yeast Saccharomonospora viridis AHK190 (Kawai et al., 2014), recombinant esterase originally isolated from Thermobifida halotolerans, which is capable of degrading PET with production of terephthalic acid and MHET (Ribitsch et al., 2012), as well as nitrobenzylesterase from Bacillus subtilis (Ribitsch et al., 2011).

A considerable number of studies have addressed the mechanisms of PS degradation. Weak sites of a PS chain are the tertiary carbon atoms bound to phenyl 


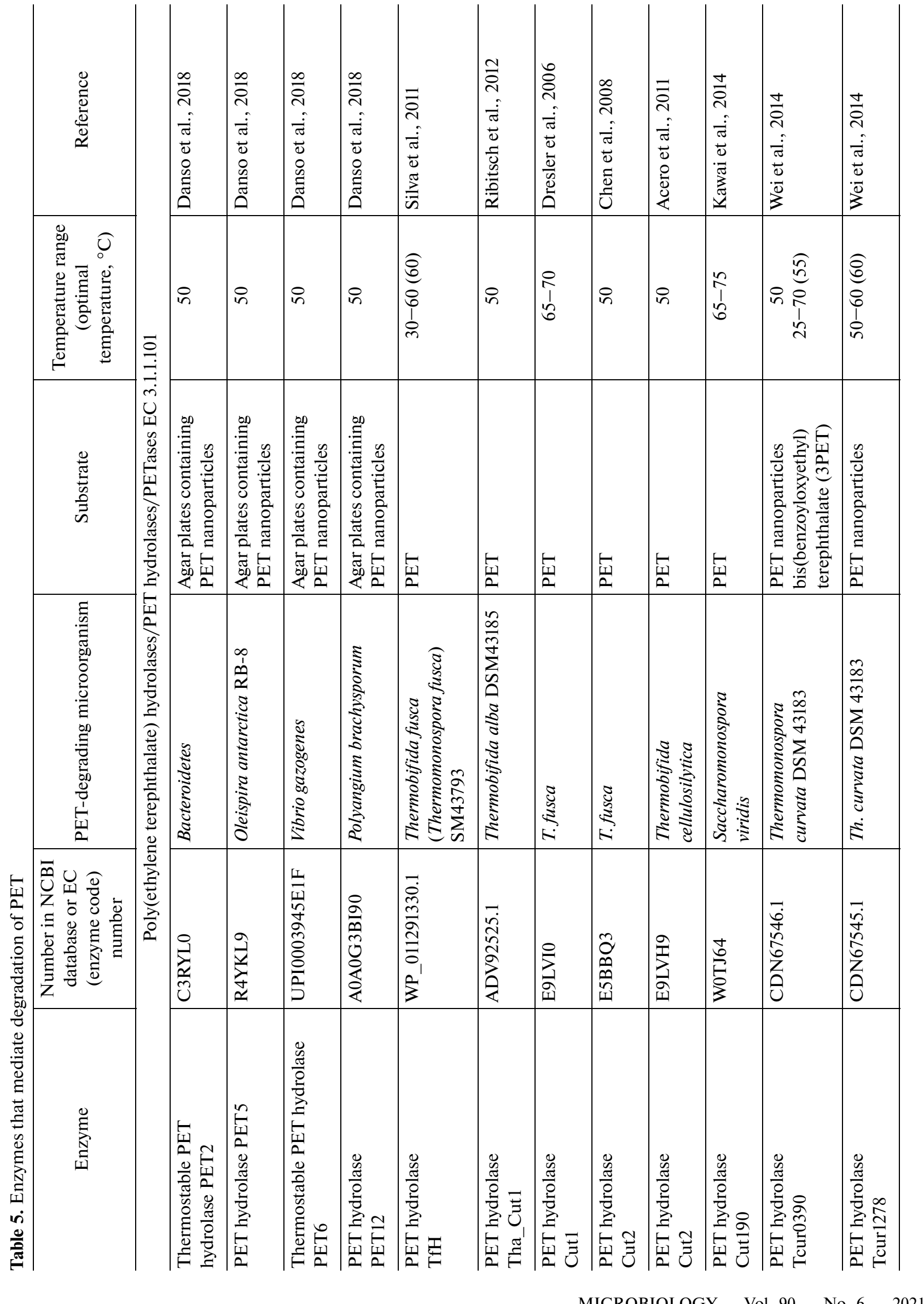




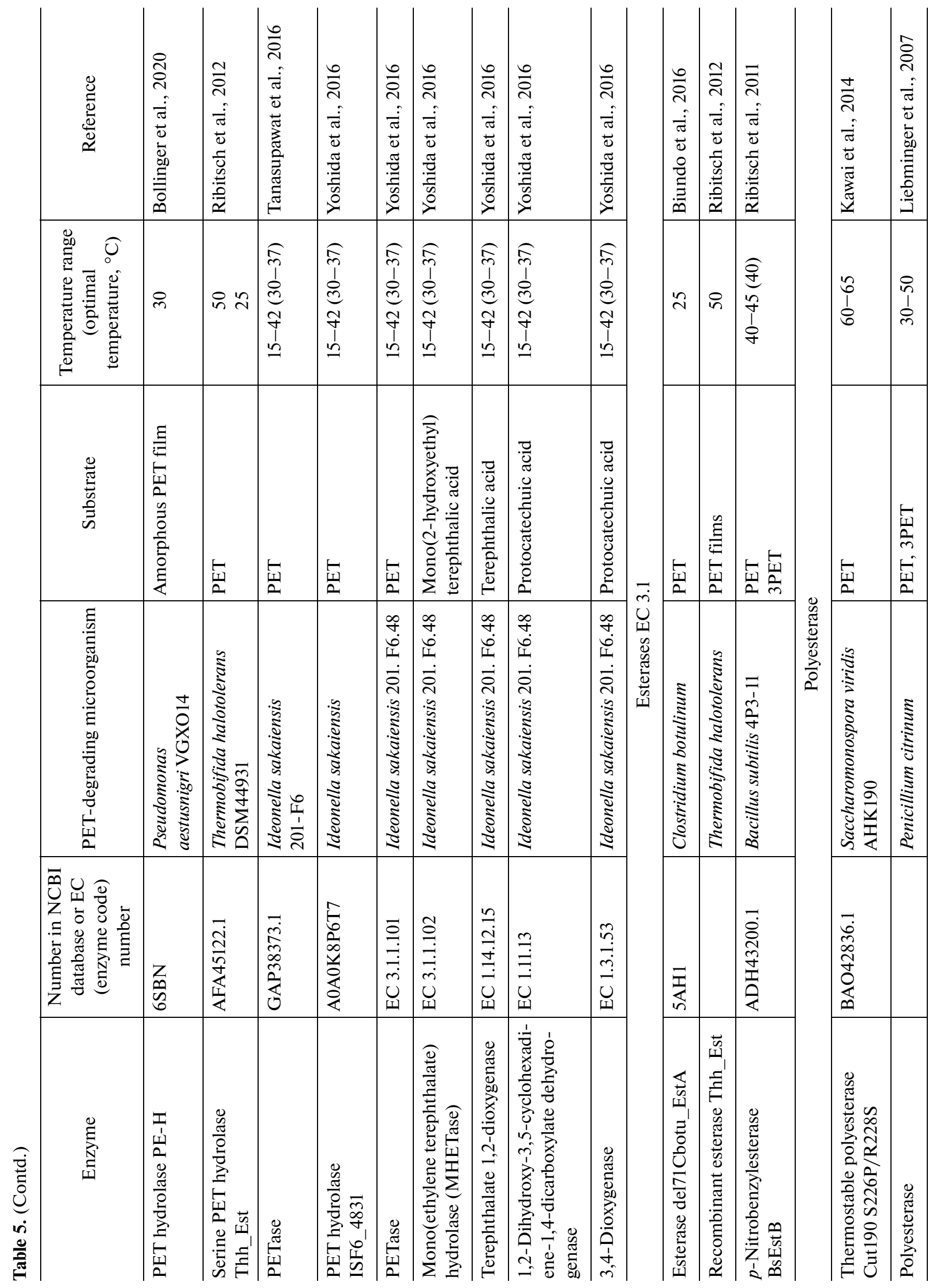

MICROBIOLOGY Vol.90 No. 62021 
KOTOVA et al.

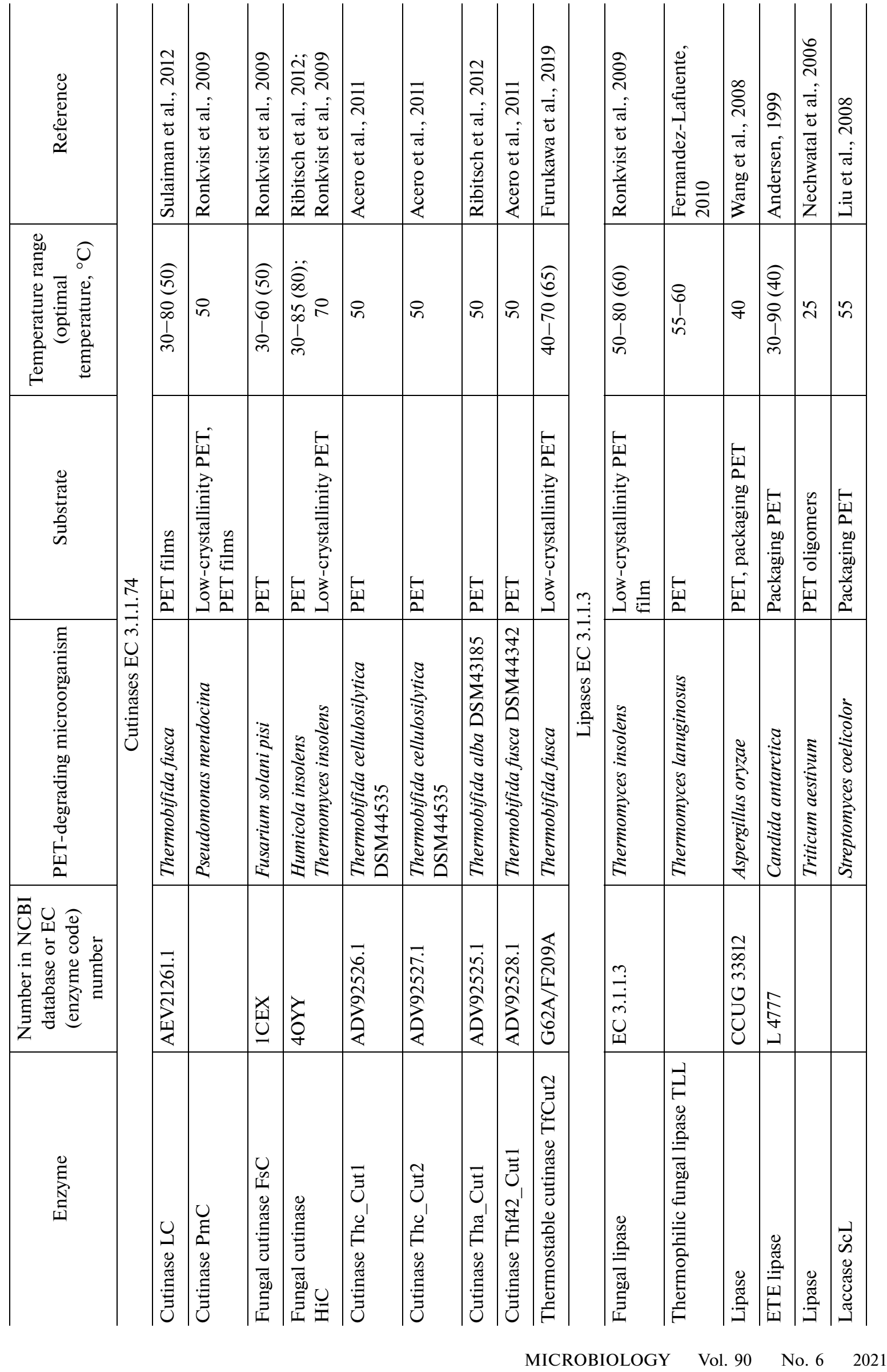


groups. They can be attacked by free radicals, and some chemical reactions at these sites can result in chain break or induce formation of carbonyl groups (Niessner and Gausepohl, 2003), which, together with peroxide groups, promote the polymer degradation (Meekum and Kenharaj, 2002; Botelho et al., 2004).

The initial stages of the process may involve enzymatic depolymerization, interactions with aggressive microbial metabolites, or chemical reactions between the polymer and the additives it contains (Milstein et al., 1992; Mooney et al., 2006; Krueger et al., 2015; Tischler et al., 2015; Chauhun et al., 2018; Ho et al., 2018). Presumably, microorganisms growing on a PS surface should synthesize enzymes or produce aggressive metabolites that promote degradation of the polymer into oligomers and monomers; however, none of the currently known microbial enzymes was shown to be capable of degrading PS. This property is expected to be found in fungal ligninperoxidases. A strong effect on polymer degradation can be induced by organic acids secreted by mold fungi: citric, oxalic, succinic, acetic, gluconic, lactic, or fumaric. Several species of molds sharing a common habitat can exchange their organic acid products, thus providing appropriate growth conditions even for those fungi that cannot develop on PS as pure cultures.

The second stage is biodegradation of oligo- and monomers, in particular, styrene. It is predominantly oxidized via the pathway of styrene side-chain oxygenation (so-called upper pathway) (Oelschlägel et al., 2018). Under aerobic conditions, styrene is directly oxidized by styrene monooxygenase with production of styrene epoxide, which is subsequently oxidized to phenylacetaldehyde by styrene oxide isomerase. Next, dehydrogenase catabolizes phenylacetaldehyde to phenylacetic acid. Phenylacetic acid is transformed into phenylacetyl-CoA by ligase, then it undergoes dearomatization in several enzymatic reactions, and ultimately enters the tricarboxylic acid cycle via formation of acetyl-CoA and succinyl-CoA (as studied in bacteria of the genera Pseudomonas, Xanthobacter, Rhodococcus, and Corynebacterium).

Pseudomonas putida CA-3 growing on styrene can accumulate polyhydroxyalkanoates by using a unique biodegradation pathway (lower pathway) (O'Leary et al., 2005). It involves oxidation of the aromatic ring with subsequent entrance into the $\beta$-oxidation cycle and transformation to acetyl-CoA. Subsequently, acetyl-CoA can enter either the tricarboxylic acid cycle or the pathway of de novo fatty acid synthesis, which will give rise to medium-chain polyhydroxyakanoates as the end product. The above-mentioned Bacillus paralicheniformis strain isolated from bottom sediments of the Arabian Sea and capable of degrading $34 \%$ of total PS film mass in 60 days was found to possess genes that encode enzymes involved in PS degradation: monooxygenase, dioxygenase, peroxidase, esterase, and hydrolase.
Genes responsible for styrene side chain oxidation frequently form a single conserved gene cluster named $\operatorname{sty} A B C(D)$. The genes sty $A$ and $\operatorname{sty} B$ encode the monooxygenase complex that mediates styrene degradation. Styrene monooxygenase is a two-component flavoprotein that catalyzes NADH- and FAD-dependent epoxidation of styrene into styrene oxide. StyA is a monooxygenase, and StyB acts as a flavin-adenine nucleotide reductase to provide StyA with the required electrons. The genes sty $C$ and sty $D$ encode styrene isomerase and phenylacetaldehyde dehydrogenase, respectively (Oelschlägel et al., 2012, 2018; Morrison et al., 2013; Crabo et al., 2017).

\section{APPROACHES TO ENHANCING EFFICIENCY OF PLASTIC BIODEGRADATION}

Investigation of plastic degradation is invariably accompanied by search for approaches to intensifying this process. First of all, the rate of polymer degradation by microorganisms depends on the area of the contact surface; therefore, to accelerate degradation, polymers are used in the form of thin films or powder (Montazer et al., 2020).

To promote degradation, plastics can be exposed to various physical factors that modify their structure and make them more susceptible to biodegradation. The most common types of treatment are exposure to UV radiation and heat. For instance, it was shown that the rate of LDPE biodegradation can be increased using preliminary photo- or thermal treatment (Volke-Sepúlveda et al., 2002; Chatterjee et al., 2010). Exposure to these factors alters the degree of crystallinity and morphological characteristics of PE, decreases the length of polymer chains, and generates oxidized carbonyl, carboxyl, and hydroxyl groups, thus accelerating microbial degradation of the polymer (Albertsson, 1980; Hadad et al., 2005, Esmaeili et al., 2013). The duration of UV treatment should be at least $250 \mathrm{~h}$, and exposure to high temperatures $\left(70-80^{\circ} \mathrm{C}\right.$ ) should last for at least $24 \mathrm{~h}$ (YamadaOnodera et al., 2001; Abrusci et al., 2011, Montazer et al., 2019).

Similar effects of UV irradiation and thermal treatment were observed for PET degradation. Its ester bonds, which represent potential targets for microbial esterases or lipases, are shielded by aromatic groups that make the entire structure resistant to biodegradation (Webb et al., 2013).

Exposure to abiotic factors, such as UV irradiation and thermal treatment, significantly enhances the effect of microbial hydrolytic enzymes (Wei and Zimmermann, 2017b).

Formation of carbonyl groups in PE is stimulated by preliminary acid treatment. In studies of microbial degradation of LDPE, the polymer powder was pretreated with $65 \%$ nitric acid solution for 10 days (Rajandas et al., 2012) or with 99\% nitric acid for 
6 days (Hasan et al., 2007). In both cases, data obtained by FTIR spectroscopy showed that PE biodegradation was enhanced. It was also found that a combination of photooxidation and chemical pretreatment with nitric acid had a synergistic effect on increasing the biodegradation rate (Hasan et al., 2007).

The effects of cultivation temperature on polymer degradation rates are currently extensively studied. For instance, a high plastic-degrading capacity was reported for thermophilic bacterial consortia of Brevibacillus spp. and Aneurinibacillus sp. (Skariyachan et al., 2018). When the rates of PE degradation by Pseudomonas aeruginosa were compared at 7, 23, 37, and $44^{\circ} \mathrm{C}$, the most significant substrate depletion (6.25\% in 30 days) was observed at $44^{\circ} \mathrm{C}$ (Tamnou et al., 2021).

To address the problem of PET degradation, it is of key importance to search for microorganisms that produce thermostable enzymes exhibiting high activity at elevated temperatures, since amorphous fragments of the polymer become more flexible and more accessible for hydrolytic enzymes at temperatures above the glass transition point $\left(65^{\circ} \mathrm{C}\right)$ (Ronkvist et al., 2009).

Microbial degradation of plastics is significantly hindered by their hydrophobicity, which impairs cell adhesion to plastic surfaces. Production of surfaceactive compounds by bacteria is of key importance for bacterial degradation of PE, since biosurfactants lower interfacial tension and facilitate bacterial adhesion to PE surfaces (Vimala and Mathew, 2016; Zhurina et al., 2020). It was shown that addition of $0.05 \% \mathrm{~min}-$ eral oil promoted biofilm formation and enhanced PE biodegradation (Hadad et al., 2005). It was also found that hydrolytic activity of PETases can be stimulated by using anionic surfactants that enable anionized PET surfaces to attract more cationic PETases (Furukawa et al., 2019).

Degradation of plastics can be accelerated by using substrate mixtures that include, in addition to the plastic, more readily available sources of carbon and energy. In particular, it was found that mixing PE with polymers of natural origin, e.g., starch, can increase its biodegradability. For instance, $\alpha$-amylase was shown to mediate degradation of blended LDPE-starch specimens in water solution; after enzymatic treatment, weight and tensile strength of the polymer specimens decreased by 48 and $87 \%$, respectively (Karimi and Biria, 2019). Data obtained by gel permeation chromatography indicated that both the molar mass and viscosity of LDPE decreased by more than 70 and $60 \%$, respectively. These results suggest that the main chain of the polymer, as well as its side chains, were cleaved by $\alpha$-amylase, indicating that this enzyme had a promiscuous cometabolizing effect on the biodegradation of LDPE blended with starch.

It was also observed that biodegradation in binary biofilms is more efficient, if the microbial partners form a trophic chain where one strain can mediate primary modification of the polymer molecule and the other one consumes the resulting intermediate products. One of the members of the microbial association may also perform the important auxiliary function of producing biosurfactants, which help metabolize compounds insoluble in water (Plakunov et al., 2020). In the course of PS degradation by mixed cultures (as a rule, at the initial stages), the polymer can be exposed to aggressive metabolites (e.g., acids) produced by members of the community that grow on the available sources of carbon and energy and do not possess enzymes acting directly on PS (Naz et al., 2013; Ho et al., 2018; Chauhan et al., 2018).

\section{CONCLUSIONS}

Accumulation of plastic waste in the environment definitely indicates that natural microbial communities cannot manage its degradation. Indeed, all available experimental data suggest that reliably documented processes of plastic degradation are very slow. Nevertheless, the results of extensive research accumulated in the recent years show that even in this seemingly hopeless battle microorganisms demonstrate their great potential. Foremost, diversity of fungi and bacteria capable of degrading various types of plastics is impressive: they represent different phyla that include large numbers of cultured members, such as Proteobacteria, Firmicutes, or Actinobacteria. It can be supposed that the actual diversity of plastic-degrading prokaryotes is even greater. It should also be noted that only a limited number of ecological niches have been analyzed for the presence of microorganisms capable of degrading plastics, and expanding the range of habitats studied could probably result in isolation of novel target microorganisms. Unfortunately, very few studies have investigated anaerobic degradation of plastics, while these processes are certainly worth researchers' attention, since anoxic habitats are widely prevalent on Earth, including anoxic landfill layers. Extremely impressive results were obtained by studying invertebrates capable of assimilating hardly degradable substrates, such as wax, due to their microbial symbionts. It can be expected that the number of such associated microbial communities is much higher, and they might be present in highly diverse habitats. It seems promising to search for novel microorganisms capable of plastic degradation in extreme habitats, where plastics are exposed both to physicochemical factors as well as to microorganisms resistant to these abiotic factors.

An example of breakthrough in research of plastic degradation mechanisms are rapidly advancing studies of enzymes that mediate degradation of PET. Recombinant PETases demonstrate high rates of polymer substrate degradation; furthermore, thanks to their thermal stability, the process can be conducted at elevated temperatures. These promising results inspire 
hope that a technology of enzymatic PET treatment will be developed in the nearest future.

It is expected that the number of studies on microbial degradation of plastics will rapidly increase. In this context, it is necessary to develop standardized protocols for experiments on biodegradation of plastics, since this would enable researchers to unite their worldwide efforts in solving this extremely difficult problem of ultimate importance.

\section{FUNDING}

This work was financially supported by the Russian Science Foundation for Basic Research, project no. 19-1418001 and Expansion project no. 20-14-50477.

\section{COMPLIANCE WITH ETHICAL STANDARDS}

Conflict of interests. The authors declare that they have no conflict of interest.

Statement on the welfare of animals. This article does not contain any studies involving animals or human participants performed by any of the authors.

\section{OPEN ACCESS}

This article is licensed under a Creative Commons Attribution 4.0 International License, which permits use, sharing, adaptation, distribution and reproduction in any medium or format, as long as you give appropriate credit to the original author(s) and the source, provide a link to the Creative Commons license, and indicate if changes were made. The images or other third party material in this article are included in the article's Creative Commons license, unless indicated otherwise in a credit line to the material. If material is not included in the article's Creative Commons license and your intended use is not permitted by statutory regulation or exceeds the permitted use, you will need to obtain permission directly from the copyright holder. To view a copy of this license, visit http://creativecommons.org/licenses/by/4.0/.

\section{REFERENCES}

Abrusci, C., Pablos, J.L., Corrales, T., López-Marín, J., Marín, I., and Catalina, F., Biodegradation of photo-degraded mulching films based on polyethylenes and stearates of calcium and iron as pro-oxidant additives, Int. Biodeterior. Biodegrad., 2011, vol. 65, pp. 451-459.

Abrusci, C., Pablos, J.L., Marin, I., Espi, E., Corrales, T., and Catalina, F., Comparative effect of metal stearates as pro-oxidant additives on bacterial biodegradation of thermal- and photo-degraded low density polyethylene mulching films, Int. Biodeterior. Biodegrad., 2013, vol. 83, pp. 2532.

https://doi.org/10.1016/j.ibiod.2013.04.002

Acero, E.H., Ribitsch, D., Steinkellner, G., Gruber, K., Greimel, K., Eiteljoerg, I., Trotscha, E., Wei, R., Zimmermann, W., Zinn, M., Cavaco-Paulo, A., Freddi, G., Schwab, H., and Guebitz, G., Enzymatic surface hydrolysis of PET: Effect of structural diversity on kinetic properties of cutinases from Thermobifida, Macromolecules, 2011, vol. 44, pp. 4632-4640.

Ahebnazar, Z., Shojaosadati, S.A., MohammadTaheri, M., and Nosrati, M., Biodegradation of low-density polyethylene (LDPE) by isolated fungi in solid waste medium, Waste Manag., 2010, vol. 30, pp. 396-401.

Albertsson, A.C. and Karlsson, S., The influence of biotic and abiotic environments on the degradation of polyethylene, Prog. Polym. Sci., 1990, vol. 15, pp. 177-192. https://doi.org/10.1016/0079-6700(90)90027-X

Ali, M.I., Ahmed, S., Robson, G., Javed, I., Ali, N., Atiq, N., and Hameed, A., Isolation and molecular characterization of polyvinyl chloride (PVC) plastic degrading fungal isolates, J. Basic Microbiol., 2014, vol. 54, pp. 18-27. Ammala, A., Bateman, S., Dean, K., Petinakis, E., Sangwan, P., and Wong, S., An overview of degradable and biodegradable polyolefins, Prog. Polym. Sci., 2011, vol. 36, pp. $1015-1049$.

https://doi.org/10.1016/j.progpolymsci.2010.12.002

Andersen, B.K., Borch, K., Abo, M., and Damgaard, B., Method of treating polyester fabrics, Patent US 5997584, 1999.

Andredy, A., Assessment of environmental biodegradation of synthetic polymers, J. Macromol. Sci., Part C: Polymer Reviews, 1994, vol. 34, pp. 25-76.

Anwar, M.S., Kapri, A., Chaudhry, V., Mishra, A., Ansari, M.W., Souche, Y., Nautiyal, C.S., Zaidi, M.G.H., and Goel, R., Response of indigenously developed bacterial consortia in progressive degradation of polyvinyl chloride, Protoplasma, 2016, vol. 253, pp. 1023-1032.

Arkatkar, A., Arutchelvi, J., Bhaduri, S., Uppara, P.V., and Doble, M., Degradation of unpretreated and thermally pretreated polypropylene by soil consortia., Int. Biodeterior. Biodegrad., 2009, vol. 63, pp. 106-111.

Arutchelvi, J., Sudhakar, M., Arkatkar, A., Doble, M., Bhadur, S., and Uppara, P.V., Biodegradation of polyethylene and polypropylene, Indian J. Biotechnol., 2008, vol. 7, pp. 9-22.

Asmita, A., Shubhamsingh, T., and Tejashree, S., Isolation of plastic degrading micro-organisms from soil samples collected at various locations in Mumbai, India, Int. Res. J. Environ. Sci., 2015, vol. 4, pp. 77-85.

Atiq, N., Safia, A., Ali, M.I., and Andleeb, S., Isolation and identification of polystyrene biodegrading bacteria from soil, Afr. J. Microbiol. Res., 2010, vol. 4, pp. 1537-1541.

Atlas, R.M. and Bartha, R., Biogeochemical cycling: nitrogen, sulfur, phosphorus, iron, and other elements, in Microbial Ecology: Fundamentals and Applications, Menlo Park, CA: The Benjamin/Cummings Publishing Company, Inc., 1987, pp. 333-360.

Austin, H.P., Allen, M.D., Donohoe, B.S., Rorrer, N.A., Kearns, F.L., Silveira, R.L., Pollard, B.C., Dominick, G., Duman, R., El Omari, K., Mykhaylyk, V., Wagner, A., Michener, W.E., Amore, A., Skaf, M.S., et al., Characterization and engineering of a plastic-degrading aromatic polyesterase, Proc. Natl. Acad. Sci. USA, 2018, vol. 115, pp. E4350-E4357.

https://doi.org/10.1073/pnas.1718804115

Auta, H.S., Emenike, C., and Fauziah, S.H., Screening for polypropylene degradation potential of bacteria isolated 
from mangrove ecosystem in Peninsular Malasia, Int. J. Biosci. Biochm. Bioinform., 2017a, vol. 7, pp. 245-251.

Auta, H.S., Emenike, C., and Fauziah, S.H., Distribution and importance of microplastics in the marine environment: a review of the sources, fate, effects, and potential solutions, Environ. Intern., 2017b, vol. 102.

https://doi.org/10.1016/j.envint.2017.02.013

Auta, H.S., Emenike, C.U., Jayanthi, B., and Fauziah, S.H., Growth kinetics and biodeterioration of polypropylene microplastics by Bacillus sp. and Rhodococcus sp. isolated from mangrove sediment, Marine Pollut. Bull., 2018, vol. 127, pp. 15-21.

Barth, M., Oeser, T., Wei, R., Then, J., Schmidt, J., and Zimmermann, W., Effect of hydrolysis products on the enzymatic degradation of polyethylene terephthalate nanoparticles by a polyester hydrolase from Thermobifida fusca, Biochem. Eng. J., 2015, vol. 93, pp. 222-228. https://doi.org/10.1016/J.BEJ.2014.10.012

Bartnev, G.M. and Frenkel S.Ya., Fizika polimerov (Physics of Polymers), El'yashevich, A.M., Ed., Leningrad: Khimiya, 1990.

Berk, S., Ebert, H., and Teitell, L., Utilization of plasticizers and related organic compounds by fungi, Ind. Eng. Chem., 1957, vol. 49, pp. 1115-1124.

Bhatia, M., Girdhar, A., Tiwari, A., and Nayarisseri, A., Implications of a novel Pseudomonas species on low density polyethylene biodegradation: an in vitro to in silico approach, SpringerPlus, 2014, vol. 3, art. 497, pp. 1-10. https://doi.org/10.1186/2193-1801-3-497

Billen, P., Khalifa, L., Van Gerven, F., Tavernier, S., and Spatari, S., Technological application potential of polyethylene and polystyrene biodegradation by macro-organisms such as mealworms and wax moth larvae, Sci. Total Environ., 2020, vol. 735., art. 139521.

https://doi.org/10.1016/j.scitotenv.2020.139521

Biundo, A., Ribitsch, D., Steinkellner, G., Gruber, K., and Guebitz, G.M., Polyester hydrolysis is enhanced by a truncated esterase: less is more, Biotechnol. J., 2017, vol. 12. https://doi.org/10.1002/biot.201600450

Biundo, A., Reich, J., Ribitsch, D., and Guebitz, G.M., Synergistic effect of mutagenesis and truncation to improve a polyesterase from Clostridium botulinum for polyester hydrolysis, Sci. Rep., 2018, vol. 8, p. 3745.

Bollinger, A., Thies, S., Knieps-Grünhagen, E., Gertzen, C., Kobus, S., Höppner, A., Ferrer, M., Gohlke, H., Smits, S.H.J., and Jaeger, K., A novel polyester hydrolase from the marine bacterium Pseudomonas aestusnigristructural and functional insights, Front. Microbiol., 2020, vol. 11, art. 114.

https://doi.org/10.3389/fmicb.2020.00114

Bonhomme, S., Cuer, A., Delort, A.M., Lemaire, J., Sancelme, M., and Scott, C., Environmental biodegradation of polyethylene, Polym. Degrad. Stab., 2003, vol. 81, pp. $441-452$.

Booth, G.H., Cooper, A.W., and Robb, J.A., Bacterial degradation of plasticized PVC, J. Appl. Bacteriol., 1968, vol. 31, pp. 305-310.

Botelho, G., Queiros, A., Machado, A., Frangiosa, P., and Ferreira, J., Enhancement of the thermooxidative degradability of polystyrene by chemical modification, Polym. Degrad. Stab., 2004, vol. 86, pp. 493-497.
Boucher, J. and Friot, D., Primary Microplastics in the Oceans: A Global Evaluation of Sources, Gland: IUCN, 2017, p. 43.

Brandon, A.M., Gao, S.H., Tian, R., Ning, D., Yang, S.S., Zhou, J., Wu, W.-M., and Criddle, C.S., Biodegradation of polyethylene and plastic mixtures in mealworms (larvae of Tenebrio molitor) and effects on the gut microbiome, Environ. Sci. Technol., 2018, vol. 52, pp. 6526-6533.

https://doi.org/10.1021/acs.est.8b02301

Brandon, J.A., Jones, W., and Ohman, M.D., Multidecadal increase in plastic particles in coastal ocean sediments, Sci. $A d v .$, 2019, vol. 5, art. eaax0587.

https://doi.org/10.1126/sciadv.aax0587

Bratsykhin, E.A. and Shulgina, E.S., Tekhnologiya plasticheskikh mass. Uchebnoe posobie dlya tekhnikumov (Technology of Plastics. Textbook for Technical Schools), Leningrad: Khimiya, 1982, 3rd edn.

Chatterjee, S., Roy, B., Roy, D., and Banerjee, R., Enzyme-mediated biodegradation of heat treated commercial polyethylene by Staphylococcal species, Polym. Degrad. Stab., 2010, vol. 95, pp. 195-200.

https://doi.org/10.1016/j.polymdegradstab.2009.11.025

Chaudhary, A.K. and Vijayakumar, R., Studies on biological degradation of polystyrene by pure fungal cultures, Environ. Dev. Sustain., 2019, vol. 22, pp. 4495-4508.

Chauhan, D., Agrawal, G., Deshmukh, S., Roy, S.S., and Priyadarshini, R., Biofilm formation by Exiguobacterium sp. DR11 and DR14 alter polystyrene surface properties and initiate biodegradation, $R S C A d v$., 2018, vol. 8, pp. 3759037599.

Chen, S., Tong, X., Woodard, R.W., Du, G.C., Wu, J., and Chen, J., Identification and characterization of bacterial cutinase, J. Biol. Chem., 2008, vol. 283, pp. 25854-25862.

Chen, S., Su, L., Chen, J., and Wu, J., Cutinase: characteristics, preparation and application, Biotechnol. Adv., 2013, vol. 31, pp. 1754-1767.

https://doi.org/10.1016/j.biotechadv.2013.09.005

Crabo, A.G., Singh, B., Nguyen, T., Emami, S., Gassner, G.T., and Sazinsky, M.H., Structure and biochemistry of phenylacetaldehyde dehydrogenase from the Pseudomonas putida S12 styrene catabolic pathway, Arch. Biochem. Biophys., 2017, vol. 616, pp. 47-58.

Danso, D., Schmeisser, C., Chow, J. Zimmermann, W., Wei, R., Leggewie, C., Li, X., Hazen, T., and Streit, W.R., New insights into the function and global distribution of polyethylene terephthalate (PET)-degrading bacteria and enzymes in marine and terrestrial metagenomes, Appl. Environ. Microbiol., 2018, vol. 84, e02773-17.

Das, G., Bordoloi, N.K., Rai, S.K., Mukherjee, A.K., and Karak, N., Biodegradable and biocompatible epoxidized vegetable oil modified thermostable poly(vinyl chloride): Thermal and performance characteristics post biodegradation with Pseudomonas aeruginosa and Achromobacter sp., $J$. Hazard. Mat., 2012, vol. 209-210, pp. 434-442.

Das, M.P. and Kumar, S., An approach to low-density polyethylene biodegradation by Bacillus amyloliquefaciens, 3 Biotech., 2015, vol. 5, pp. 81-86.

Delacuvellerie, A., Cyriaque, V., Gobert, S., Benali, S., and Wattiez, R., The plastisphere in marine ecosystem hosts potential specific microbial degraders including Alcanivorax borkumensis as a key player for the low-density polyethylene 
degradation, J. Hazard. Mater., 2019, vol. 380, e120899. https://doi.org/10.1016/j.jhazmat.

de Stephanis, R., Giménez, J., Carpinelli, E., GutierrezExposito, C., and Cañadas, A., As main meal for sperm whales: plastics debris, Mar. Pollut. Bull., 2013, vol. 69, pp. 206-214.

Description and brands of polymers, Polymer Materials. Products, Equipment, Technologies. http://www.polymerbranch.com/catalogp/view/3.html.

Devi, R.S., Kannan, V.R., Natarajan, K., Nivas, D., Kannan, K., Chandru, S., and Antony, A.R., The role of microbes in plastic degradation, in Environmental Waste Management, Ram Chandra, Ed., Boca Raton: Taylor \& Francis Group, LLC, 2016, pp. 341-370.

Dresler, K., van den Heuvel, J., Muller, R.J., and Deckwer, W.D., Production of a recombinant polyestercleaving hydrolase from Thermobifida fusca in Escherichia coli, Bioproc. Biosyst. Eng., 2006, vol. 29, pp. 169-183.

El-Shafei, H., EI-Nasser, N.H.A., Kansoh, A.L., and Ali, A.M., Biodegradation of disposable polyethylene by fungi and Streptomyces species, Polym. Degrad. Stab., 1998, vol. 62, pp. 361-365.

Esmaeili, A., Pourbabaee, A.A., Alikhani, H.A., Shabani, F., and Esmaeili, E., Biodegradation of low-density polyethylene (LDPE) by mixed culture of Lysinibacillus xylanilyticus and Aspergillus niger in soil, PLoS One, 2013, vol. 8, e71720.

Eubeler, J.P., Bernhard, M., and Knepper, T.P., Environmental biodegradation of synthetic polymers: Biodegradation of different polymer groups, Trends Analyt. Chem., 2010, vol. 29, pp. 84-100.

Fernandez-Lafuente, R., Lipase from Thermomyces lanuginosus: uses and prospects as an industrial biocatalyst, $J$. Mol. Catal. B: Enzymatic, 2010, vol. 62, pp. 197-212.

Fontanella, S., Bonhomme, S., Koutny, M., Husarova, L., Brusso, J.M., Courdavault, J.P., Pitteri, S., Samuel, G., Pichon, G., Lemaire, J., and Delort, A.-M., Comparison of the biodegradability of various polyethylene films containing pro-oxidant additives, Polym. Degrad. Stab., 2010, vol. 95 , pp. $1011-1021$.

https://doi.org/10.1016/j.polymdegradstab.2010.03.009

Freddi, G., Schwab, H., Guebitz, G.M., Hydrolysis of polyethyleneterephthalate by $p$-nitrobenzylesterase from Bacillus subtilis, Biotechnol. Prog., 2011, vol. 27, pp. 951-960.

Furukawa, M., Kawakami, N., Tomizawa, A., and Miyamoto, K., Efficient degradation of poly(ethylene terephthalate) with Thermobifda fusca cutinase exhibiting improved catalytic activity generated using mutagenesis and additive-based approaches, Sci. Rep., 2019, vol. 9, art. 16038.

Gall, S.C. and Thompson, R.C., The impact of debris on marine life, Marine Pollut. Bull., 2015, vol. 92, pp. 170-179.

Gallo, F., Fossi, C., Weber, R., Santillo, D., Sousa, J., Ingram, I., Nadal, A., and Romano, D., Marine litter plastics and microplastics and their toxic chemicals components: the need for urgent preventive measures, Environ. Sci. Eur., 2018, vol. 30, art. 13.

Galygin, V.E., Baronin, G.S., Tarov, V.P., and Zavrazhin, D.O., Sovremennye tekhnologii polucheniya $i$ pererabotki polimernykh $i$ kompozitsionnykh materialov (Modern Techniques of Production and Recycling of Poly- mer and Composite Materials), Tambov: Tambov State Tech. Univ., 2012.

Geyer, R., Jambeck, J., and Law, K.L., Production, use, and fate of all plastics ever made, Sci. $A d v$., 2017, vol. 3, art. e1700782.

https://doi.org/10.1126/sciadv.1700782

Ghatge, S., Yang, Y., Ahn, J.-A., and Hur, H.-G., Biodegradation of polyethylene: a brief review, Appl. Biol. Chem., 2020 , vol. 63, art. 27.

https://doi.org/10.1186/s13765-020-00511-3

Giacomucci, L., Raddadi, N., Soccio, M., Lotti, N., and Fava, F., Polyvinyl chloride biodegradation by Pseudomonas citronellolis and Bacillus flexus, New Biotechnol., 2019, vol. 52, pp. 35-41.

Gilan, I., Hadar, Y., and Sivan, A., Colonization, biofilm formation and biodegradation of polyethylene by a strain of Rhodococcus ruber, Appl. Microbiol. Biotechnol., 2004, vol. 65, pp. 97-104.

Gravouil, K., Ferru-Clément, R., Colas, S., Helye, R., Kadri, L., Bourdeau, L., Moumen, B., Mercier, A., and Ferreira, T., Transcriptomics and lipidomics of the environmental strain Rhodococcus ruber point out consumption pathways and potential metabolic bottlenecks for polyethylene degradation, Environ. Sci. Technol., 2017, vol. 51, pp. 5172-5181.

Guillet, J.E., Regulski, T.W., and McAneney, T.B., Biodegradability of photodegraded polymers. II. Tracer studies of biooxidation of Ecolyte PS polystyrene, Environ. Sci. Technol., 1974, vol. 8, pp. 923-925.

https://doi.org/10.1016/j.chemosphere.2008.07.035

Hadad, D., Geresh, S., and Sivan, A., Biodegradation of polyethylene by the thermophilic bacterium Brevibacillus borstelensis, J. Appl. Microbiol., 2005, vol. 98, pp. 10931100.

Haines, J.R. and Alexander, M., Microbial degradation of high-molecular-weight alkanes, Appl. Microbiol., 1975, vol. 28, pp. 1084-1085.

Harrison, J.P., Boardman, C., O'Callaghan, K., Delort, A.M., and Song, J., Biodegradability standards for carrier bags and plastic films in aquatic environments: a critical review, R. Soc. Open Sci., 2018, vol. 5, art. 171792. https://doi.org/10.1098/rsos.171792

Harshvardhan, K. and Jha, B., Biodegradation of low-density polyethylene by marine bacteria from pelagic waters, Arabian Sea, India, Marine Pollut. Bull., 2013, vol. 77, pp. 100-106.

Hasan, F., Shah, A.A., Hameed, A., and Ahmed, S., Synergistic effect of photo and chemical treatment on the rate of biodegradation of low density polyethylene by Fusarium sp. AF4, J. Appl. Polym. Sci., 2007, vol. 105, pp. 1466-1470. https://doi.org/10.1002/app.26328

Herrero Acero, E., Ribitsch, D., Steinkellner, G., Gruber, K., Greimel, K., Eiteljoerg, I., Trotscha, E., Wei, R., Zimmermann, W., Zinn, M., Cavaco-Paulo, A., Freddi, G., Schwab, H., and Guebitz, G., Enzymatic surface hydrolysis of PET: effect of structural diversity on kinetic properties of cutinases from Thermobifida, Macromolecules, 2011, vol. 44, pp. 4632-4640.

Hidayat, T.R., Indrawati, I., and Herlina, T., Biodegradation styrofoam by soil bacteria from Sarimukti Cipatat Bandung final disposal site, AL-Kauniyah J. Biol., 2020, vol. 13, pp. 218-227. 
Ho, B.T., Roberts, T.K., and Lucas, S., An overview on biodegradation of polystyrene and modified polystyrene: the microbial approach, Crit. Rev. Biotechnol., 2018, vol. 38, pp. 308-320.

Horton, A.A., Walton, A., Spurgeon, D.J., Lahive, E., and Svendsen, C., Microplastics in freshwater and terrestrial environments: evaluating the current understanding to identify the knowledge gaps and future research priorities, Sci. Total Environ., 2017, vol. 586, pp. 127-141.

Hu, X., Thumarat, U., Zhang, X., Tang, M., and Kawai, F., Diversity of polyester-degrading bacteria in compost and molecular analysis of a thermoactive esterase from Thermobifida alba AHK119, Appl. Microbiol. Biotechnol., 2010, vol. 87 , pp. $771-779$.

https://doi.org/10.1007/s00253-010-2555-X

Iiyoshi, Y., Tsutsumi, Y., and Nishida, T., Polyethylene degradation by lignin-degrading fungi and manganese peroxidase, J. Wood Sci., 1998, vol. 44, pp. 222-229.

Jambeck, J.R., Geyer, R., Wilcox, C., Siegler, T.R., Perryman, M., Andrady, A., Narayan, R., and Law, K.L., Marine pollution. Plastic waste inputs from land into the ocean, Science, 2015, vol. 347, pp. 768-771.

Jeon, H.J. and Kim, M.N., Functional analysis of alkane hydroxylase system derived from Pseudomonas aeruginosa E7 for low molecular weight polyethylene biodegradation, Int. Biodeterior. Biodegrad., 2015, vol. 103, pp. 141-146.

Jeon, H.J. and Kim, M.N., Isolation of mesophilic bacterium for biodegradation of polypropylene, Int. Biodeter. Biodegr., 2016, vol. 115, pp. 244-249.

https://doi.org/10.1016/j.ibiod.2016.08.025

Jeyakumar, D., Chirsteen, J., and Doble, M., Synergistic effects of pretreatment and blending on fungi mediated biodegradation of polypropylenes, Bioresour. Technol., 2013, vol. 148 , pp. $78-85$.

Kaplan, D.L., Roy, H., and Jim, S., Biodegradation of polystyrene, poly(metnyl methacrylate), and phenol formaldehyde, Appl. Environ. Microbiol., 1979, vol. 38, pp. 551553.

Karimi, M. and Biria, D., The promiscuous activity of alpha-amylase in biodegradation of low density polyethylene in a polymer-starch blend, Nat. Sci. Rep., 2019, vol. 9, art. 2612.

Kawai, F., Watanabe, M., Shibata, M., Yokoyama, S., Sudate, Y., and Hayashi, S., Comparative study on biodegradability of polyethylene wax by bacteria and fungi, Polym. Degrad. Stab., 2004, vol. 86, pp. 105-114.

https://doi.org/10.1016/j.polymdegradstab.2004.03.015

Kawai, F., Oda, M., Tamashiro, T., Waku, T., Tanaka, N., Yamamoto, M., Mizushima, H., Miyakaw, T., and Tanokura, M., A novel $\mathrm{Ca}^{2+}$-activated, thermostabilized polyesterase capable of hydrolyzing polyethylene terephthalate from Saccharomonospora viridis AHK190, Appl. Microbiol. Biotechnol., 2014, vol. 98, pp. 10053-10064.

Kawai, F., Kawabata, T., and Oda, M., Current knowledge on enzymatic PET degradation and its possible application to waste stream management and other fields, Appl. Microbiol. Biotechnol., 2019, vol. 103, pp. 4253-4268.

Kawai, F., Kawabata, T., and Oda, M., Current state and perspectives related to the polyethylene terephthalate hydrolases available for biorecycling, ACS Sustainable Chem. Eng., 2020, vol. 8, pp. 8894-8908.
Khatoon, N., Jamal, A., and Ali, M.I., Lignin peroxidase isoenzyme: a novel approach to biodegrade the toxic synthetic polymer waste, Environ. Technol., 2019, vol. 40, pp. 1366-1375.

Khimiya $i$ tekhnologiya sinteticheskikh vysokomolekulyarnykh soedinenii. Karbotsepnye polimery (Chemistry and Technology of Synthetic High-Molecular-Weight Compounds. Carbon Chain Polymers), Shkolina, M.A., Ed., Moscow: Nauka, 1967.

Kiessling, T., Gutow, L., and Thiel, M., Marine litter as habitat and dispersal vector, in Marine Anthropogenic Litter, Bergmann, M., Gutow, L., and Klages, M., Eds., Cham: Springer, 2015.

Kim, H.R., Lee, H.M., Yu, H.C., Jeon, E., Lee, S., Li, J.J., and Kim, D.-H., Biodegradation of polystyrene by Pseudomonas sp. isolated from the gut of superworms (Larvae of Zophobas atratus), Environ. Sci. Technol., 2020, vol. 54, pp. 6987-6996.

https://doi.org/10.1021/acs.est.0c01495

Kirbaş, Z., Keskin, N., and Güner, A., Biodegradation of polyvinylchloride (PVC) by white rot fungi, Bull. Environm. Contamin. Toxicol., 1999, vol. 63, pp. 335-342.

Kleeberg, I., Hetz, C., Kroppenstedt, R.M., Müller, R.J., and Deckwer, W.-D., Biodegradation of aliphatic-aromatic copolyesters by Thermomonospora fusca and other thermophilic compost isolates, Appl. Environ. Microbiol., 1998, vol. 64 , pp. $1731-1735$.

https://doi.org/10.1128/AEM.64.5.1731-1735.1998

Koutny, M., Sancelme, M., Dabin, C., Pichon, N., Delort, A., and Lemaire, J., Acquired biodegradability of polyethylenes containing pro-oxidant additives, Polym. Degrad. Stab., 2006, vol. 91, pp. 1495-1503.

https://doi.org/10.1016/j.polymdegradstab.2005.10.007

Kowalczyk, A., Chyc, M., Ryszka, P., and Latowski, D., Achromobacter xylosoxidans as a new microorganism strain colonizing high-density polyethylene as a key step to its biodegradation, Environ. Sci. Pollut. Res., 2016, vol. 23, pp. 11349-11356.

Krueger, M.C., Hofmann, U., Moeder, M., and Schlosser, D., Potential of wood-rotting fungi to attack polystyrene sulfonate and its depolymerisation by Gloeophyllum trabeum via hydroquinone-driven fenton chemistry, PLoS One, 2015, vol. 10, e0131773.

Kudryashova, D.P., Trends of the world market of ultrahigh-molecular-weight polyethylene, Vest. Khim. Prom., 2020. http://vestkhimprom.ru/posts/tendentsii-mirovogorynka-sverkhvysokomolekulyarnogo-polietilena.

Kühn, S., Rebolledo, E.L.B., and van Franeker, J.A., Deleterious effects of litter on marine life, in Marine Anthropogenic Litter, Bergmann, M., Gutow, L., and Klages, M., Eds., Cham: Springer, 2015, pp. 75-116.

Kumar, G.A., Hinduja, M., Sujitha, K., Rajan, N.N., and Dharani, G., Biodegradation of polystyrene by deep-sea Bacillus paralicheniformis $\mathrm{G} 1$ and genome analysis, Sci. Total Environ., 2021, vol. 774, e145002.

Kundungal, H., Gangarapu, M., Sarangapani, S., Patchaiyappan, A., and Devipriya, S.P., Efficient biodegradation of polyethylene (HDPE) waste by the plastic-eating lesser waxworm (Achroia grisella), Environ. Sci. Pollut. Res. Int., 2019, vol. 26, pp. 18509-18519.

https://doi.org/10.1007/s11356-019-05038-9 
Laist, D., Overview of the biological effects of lost and discarded plastic debris in the marine environment, Marine Poll. Bull., 1987, vol. 18, pp. 319-326.

Laptev, A.B., Nikolaev, E.V., Kurshev, E.V., and Goryashnik, Yu.S., Characteristics of biodegradation of polyesterbased thermoplastics in various climate zones, 2019. http://viam-works.ru.

Lau, W.W.Y., Shiran, Y., Bailey, R.M., Cook, E., Stuchtey, M.R., Koskella, J., Velis, C.A., Godfrey, L., Boucher, J., Murphy, M.B., Thompson, R.C., Jankowska, E., Castillo Castillo, A., Pilditch, T.D., Dixon, B., et al., Evaluating scenarios toward zero plastic pollution, Science, 2020, vol. 369, pp. 1455-1461.

Lee, J.H., Lim, K.S., Hahm, W.G., and Kim, S.H., Properties of recycled and virgin poly(ethylene terephthalate) blend fibers, J. Appl. Polym. Sci., 2013, vol. 128, pp. 12501256.

Liebminger, S., Eberl, A., Sousa, F., Heumann, S., Fischer-Colbrie, G., Cavaco-Paulo, A., and Guebitz, G.M., Hydrolysis of PET and bis-(benzoyloxyethyl) terephthalate with a new polyesterase from Penicillium citrinum, Biocatal. Biotransform., 2007, vol. 25, pp. 171-177.

Liu, Y., Wu, G., and Gu, L., Enzymatic treatment of PET fabrics for improved hydrophilicity, AATCC Rev., 2008, vol. 8, pp. 44-48.

Lohse, D.J., Polyolefins, in Applied Polymer Science: 21st Century, Craver, C.D. and Carraher, C.E., Eds., Amsterdam, New York, Elsevier, 2000, pp. 73-91.

https://doi.org/10.1016/B978-008043417-9/50008-8

Lou, Y., Pererva, E., Yang, S.-S., Lu, B., Liu, B., Ren, N., Corvini, P.F.-X., and Xing, D., Bio-degradation of polyethylene and polystyrene by greater wax moth larvae (Galleria mellonella L.) and the effect of co-diet supplementation on the core gut microbiome, Environ. Sci. Technol., 2020, vol. 54, pp. $2821-2831$.

https://doi.org/10.1021/acs.est.9b07044

Lucas, N., Bienaime, C., Belloy, C., Queneudec, M., Silvestre, F., and Nava-Saucedo, J.-E., Polymer biodegradation: mechanisms and estimation techniques: a review, Chemosphere, 2008, vol. 73, pp. 429-442.

Lusher, A.L., Hernandez-Milian, G., Berrow, S., Rogan, E., and O'Connor I., Incidence of marine debris in cetaceans stranded and bycaught in Ireland: recent findings and a review of historical knowledge, Environ. Pollut., 2018, vol. 232, pp. 467-476.

Luzia, M.R.F., Sarrouh, B., and Lofrano, R.C.Z., Evaluation of the biodegradation of phthalic contaminants originated from polyvinyl chloride commercial films, Acta Sci. Technol., 2020, vol. 42. e47010.

Macali, A., Semenov, A., Venuti, V., Crupi, V., D’Amico, F., Rossi, B., Corsi, I., and Bergami, E., Episodic records of jellyfish ingestion of plastic items reveal a novel pathway for trophic transference of marine litter, Sci. Rep., 2018, vol. 8, art. 6105 .

https://doi.org/10.1038/s41598-018-24427-7

Manzur, A., Limón-González, M., and Favela-Torres, E., Biodegradation of physicochemically treated LDPE by a consortium of filamentous fungi, J. Appl. Polym. Sci., 2004, vol. 92 , pp. $265-271$.

https://doi.org/10.1002/app.13644

Marten, E., Müller, R.J., and Deckwer, W.D., Studies on the enzymatic hydrolysis of polyesters. II. Aliphatic-aro- matic copolyesters, Polym. Degrad. Stab., 2005, vol. 88, pp. 371-381.

Maurya, A., Bhattacharya, A., and Khare, S.K., Enzymatic remediation of polyethylene terephthalate (PET)-based polymers for effective management of plastic wastes: an overview, Front. Bioeng. Biotechnol., 2020, vol. 8, art. 602325.

Meekum, U. and Kenharaj, R., Comparative study of polystyrene foam degradation in the open-air and artificial weathering, Arabian J. Sci. Eng., 2002, vol. 27, pp. 25-32.

Mel'nikova, M.A., Polimernye materialy: svoistva, practicheskoe primenenie (Polymer Materials: Properties and Applications), Blagoveshchensk: Amur Univ., 2013.

Milstein, O., Gersonde, R., Huttermann, A., Chen, M.J., and Meister, J.J., Fungal biodegradation of lignopolystyrene graft copolymers, Appl. Environ. Microbiol., 1992, vol. 58, pp. 3225-3232.

Mohan, A.J., Sekhar, V.C., Bhaskar, T., and Nampoothiri, K. M., 2016. Microbial assisted high impact polystyrene (HIP) degradation, Bioresour. Technol., 2016, vol. 213, pp. 204-207.

Modern Polyesters: Chemistry and Technology of Polyesters and Copolyesters, Scheirs, J. and Long., T.E., Eds., Hoboken: John Wiley \& Sons, Ltd., 2003.

https://doi.org/10.1002/0470090685

Mohanan, N., Sharma, P.K., and Levin, D.B., Characterization of an intracellular poly(3-hydroxyalkanoate) depolymerase from the soil bacterium, Pseudomonas putida LS46, Polym. Degrad. Stab., 2020, vol. 175, art. 109127. https://doi.org/10.1016/j.polymdegradstab.2020.109127

Montazer, Z., Habibi Najafi, M.B., and Levin, D.B., Microbial degradation of low-density polyethylene and synthesis of polyhydroxyalkanoate polymers, Can. J. Microbiol., 2019, vol. 65, pp. 1-11.

https://doi.org/10.1139/cjm-2018-0335

Montazer, Z., Habibi Najafi, M.B., and Levin, D.B., Challenges with verifying microbial degradation of polyethylene, Polymers, 2020, vol. 12, art. 123.

https://doi.org/10.3390/polym 12010123

Mooney, A., Ward, P.G., and O'Connor, K.E., Microbial degradation of styrene: biochemistry, molecular genetics, and perspectives for biotechnological applications, Appl. Microbiol. Biotechnol., 2006, vol. 72, pp. 1-10.

https://doi.org/10.1007/s00253-006-0443-1

Mor, R. and Sivan, A., Biofilm formation and partial biodegradation of polystyrene by the actinomycete Rhodococcus ruber: biodegradation of polystyrene, Biodegradation, 2008, vol. 19, pp. 851-858.

Moreno, R. and Rojo, F., Enzymes for aerobic degradation of alkanes in bacteria, in Aerobic Utilization of Hydrocarbons, Oils, and Lipids, Handbook of Hydrocarbon and Lipid Microbiology, Rojo, F., Ed., Springer Nature Switzerland AG, 2019, pp. 118-142.

Morrison, E., Kantz, A., Gassner, G.T., and Sazinsky, M.H., Structure and mechanism of styrene monooxygenase reductase: new insight into the FADtransfer reaction, Biochemistry, 2013, vol. 52, pp. 60636075.

Motta, O., Proto, A., De Carlo, F., Santoro, E. Brunetti, L., and Capunzo, M., Utilization of chemically oxidized polystyrene as co-substrate by filamentous fungi, 
Int. J. Hyg. Environ. Health, 2009, vol. 212, pp. 61-66. https://doi.org/10.1016/j.ijheh.2007.09.014

Muhonja, C.N., Makonde, H., Magoma, G., and Imbuga, M., Biodegradability of polyethylene by bacteria and fungi from Dandora dumpsite Nairobi-Kenya, PLoS One, 2018, vol. 13, e0198446.

Mukherjee, S. and Kundu, P.P., Alkaline fungal degradation of oxidized polyethylene in black liquor: studies on the effect of lignin peroxidases and manganese peroxidases, $J$. Appl. Polym. Sci., 2014, vol. 131, p. 40738.

Müller, R.-J., Biodegradability of polymers: regulations and methods for testing, Biopolymers Online, 2005, vol. 12, pp. 365-388.

Müller, R. J., Biological degradation of synthetic polyesters - Enzymes as potential catalysts for polyester recycling, Proc. Biochem., 2006, vol. 41, pp. 2124-2128.

https://doi.org/10.1016/j.procbio.2006.05.018

Nakamiya, K., Hashimoto, S., Ito, H., Edmonds, J.S., Yasuhara, A., and Morita, M., Microbial treatment of bis(2-ethylhexyl) phthalate in polyvinyl chloride with isolated bacteria, J. Biosci. Bioeng., 2005, vol. 99, pp. 115-119.

Nanda, S. and Sahu, S.S., Biodegradability of polyethylene by Brevibacillus, Pseudomonas, and Rhodococcus spp., N.Y. Sci. J., 2010, vol. 3, pp. 95-98.

Naz, I., Batool, S.A., Naeem, A., Khatoon, N., Atiq, N., Hameed, A., and Ahmed, S., Monitoring of growth and physiological activities of biofilm during succession on polystyrene from activated sludge under aerobic and anaerobic conditions, Environ. Monit. Assess., 2013, vol. 185, pp. 6881-6892.

Nikolic, V., Velickovic, S., and Popovic, A., Biodegradation of polystyrene-graft-starch copolymers in three different types of soil, Environ. Sci. Pollut. Res. Int., 2014, vol. 21, pp. 9877-9886.

Nikolic, V., Velickovic, S., Antonovic, D., and Popovic, A., Biodegradation of starch-graft-polystyrene and starchgraft-poly(methacrylic acid) copolymers in model river water, J. Serb. Chem. Soc., 2013, vol. 78, pp. 1425-1441.

Nechwatal, A., Blokesch, A., Nicolai, M., Krieg, A., Kolbe, A., Wolf, M., and Gerhardt, M., A contribution to the investigation of enzyme-catalysed hydrolysis of poly(ethylene terephthalate) oligomers, Macromol. Mater. Eng., 2006, vol. 291, pp. 1486-1494.

Niessner, N. and Gausepohl, H., Polystyrene and styrene copolymers-an overview, in Modern Styrenic Polymers: Polystyrenes and Styrenic Copolymers, Scheirs, J., Priddy, D.B., Eds., Chichester, UK: John Wiley \& Sons, 2003, Ch. 2, pp. 25-41.

Nowak, B., Pajak, J., Drozd-Bratkowicz, M., and Rymarz, G., Microorganisms participating in the biodegradation of modified polyethylene films in different soils under laboratory conditions, Int. Biodeteror. Biodegr., 2011, vol. 65 , pp. 757-767.

Oelschlägel, M., Gröning, J.A.D., Tischler, D., Kaschabek, S.R., and Schlömann, M., Styrene oxide isomerase of Rhodococcus opacus 1CP, a highly stable and considerably active enzyme, Appl. Environ. Microbiol., 2012, vol. 78, pp. 4330-4337.

Oelschlägel, M., Zimmerling, J., and Tischler, D., A review: the styrene metabolizing cascade of side-chain oxygenation as biotechnological basis to gain various valuable compounds, Front. Microbiol., 2018, vol. 9, art. 490.
Ojeda, T., Freitas, A., Birck, K., Dalmolin, E., Jacques, R., Bento, F., and Camargo, F., Degradability of linear polyolefins under natural weathering, Polym. Degrad. Stab., 2011, vol. 96, pp. 703-707.

https://doi.org/10.1016/j.polymdegradstab.2010.12.004

O'Leary, N.D., O'Connor, K.E., Ward, P., Goff, M., and Dobson, A.D., Genetic characterization of accumulation of polyhydroxyalkanoate from styrene in Pseudomonas putida CA-3, Appl. Environ. Microbiol., 2005, vol. 71, pp. 43804387.

Orr, I.G., Hadar, Y., and Sivan, A., Colonization, biofilm formation and biodegradation of polyethylene by a strain of Rhodococcus ruber, Appl. Microbiol. Biotechnol., 2004, vol. 65 , pp. 97-104.

https://doi.org/10.1007/s00253-004-1584-8

Otake, Y., Kobayashi, T., Asabe, H., and Murakami, N., Biodegradation of low density polyethylene, polystyrene, polyvinyl chloride, and urea formaldehyde resin buried under soil for over 32 years, Appl. Polym. Sci., 1995, vol. 56, pp. 1789-1796.

Paco, A., Duarte, K., da Costa, J.P., Santos, P.S.M., Pereira, R., Pereira, M.E., Freitas, A.C., Duarte, A.C., and Rocha-Santos, T.A.P., Biodegradation of polyethylene microplastics by the marine fungus Zalerion maritimum, Sci. Total Environ., 2017, vol. 586, pp. 10-15.

Pardo-Rodriguez, M.L. and Zorro-Mateus, P.J.P., Biodegradation of polyvinyl chloride by Mucor sp. and Penicillium sp. isolated from soil, Revista de Investigacion Desarrollo e Innovacion: RIDI, 2021, ISSN 2027-8306, ISSN-e 23899417, pp. 387-400.

Park, S.Y. and Kim, C.G., Biodegradation of micro-polyethylene particles by bacterial colonization of a mixed microbial consortium isolated from a land fill site, Chemosphere, 2019., vol. 222, pp. 527-533.

Peciulyte, D., Microbial colonization and biodeterioration of plasticized polyvinyl chloride plastics, Ekologija, 2002, vol. 4, pp. 7-15.

Peixoto, J., Silva, L.P., and Krüger, R.H., Brazilian Cerrado soil reveals an untapped microbial potential for unpretreated polyethylene biodegradation, J. Hazard. Mater., 2017, vol. 324, pp. 634-644.

https://doi.org/10.1016/j.jhazmat.2016.11.037

Peng, B.-Y., Su, Y., Chen, Z., Chen, J., Zhou, X., Benbow, M.E., Criddle, C.S., Wu, W.-M., and Zhang, Y., Biodegradation of polystyrene by dark (Tenebrio obscurus) and yellow (Tenebrio molitor) mealworms (Coleoptera: Tenebrionidae), Environ. Sci. Technol., 2019, vol. 53, pp. 52565265.

https://doi.org/10.1021/acs.est.8b06963

Peng, B.-Y., Chen, Z., Chen, J., Yu, H., Zhou, X., Criddle, C.S., Wu, W.-M., and Zhang, Y., Biodegradation of polyvinyl chloride (PVC) in Tenebrio molitor (Coleoptera: Tenebrionidae) larvae, Environ. Int., 2020, vol. 145, p. 106106.

Peng, X., Chen, M. S., Chen, S., Dasgupta, H.X., Ta, K., Du, M., Li, J., Guo, Z., and Bai, S., Microplastics contaminate the deepest part of the world's ocean, Geochem. Persp. Let., 2018, vol. 9, pp. 1-5.

https://doi.org/10.7185/geochemlet.1829

Pirillo, V., Pollegioni, L., and Molla, G., Analytical methods for the investigation of enzyme-catalyzed degradation of polyethylene terephthalate, FEBS J., 2021. Epub ahead 
of print. PMID: 33792200.

https://doi.org/10.1111/febs. 15850

Plakunov, V.K., Gannesen, A.V., Mart'yanov, S.V., and Zhurina, M.V., Biocorrosion of synthetic plastics: degradation mechanisms and methods of protection, Microbiology (Moscow), 2020, vol. 89, pp. 647-659.

Plastics Europe. https://www.plasticseurope.org/en/newsroom/events/2021.

Pometto, A.L., Lee, B.T., and Johnson, K.E., Production of an extracellular polyethylene-degrading enzyme(s) by Streptomyces species, Appl. Environ. Microbiol., 1992, vol. 58, pp. 731-733.

Pramila, R. and Ramesh, K.V., Biodegradation of low density polyethylene (LDPE) by fungi isolated from municipal landfill area, J. Microbiol. Biotechnol. Res., 2011, vol. 1, pp. 131-136.

Pramila, R. and Ramesh, K.V., Potential degradation of low density polyethylene (LDPE) by Acinetobacter baumanii, Afr. J. Bacteriol. Res., 2015, vol. 7, pp. 24-28.

Raddadi, N. and Fava, F., Biodegradation of oil-based plastics in the environment: existing knowledge and needs of research and innovation, Sci. Total Environ., 2019, vol. 679, pp. 148-158.

Rajandas, H., Parimannan, S., Sathasivam, K., Ravichandran, M., and Yin, L.S., A novel FTIR-ATR spectroscopy based technique for the estimation of low-density polyethylene biodegradation, Polym. Test., 2012, vol. 31, pp. 10941099.

https://doi.org/10.1016/j.polymertesting

Reddy, M.M., Deighton, M., Gupta, R.K., Bhattacharya, S.N., and Parthasarathy, R., Biodegradation of oxobiodegradable polyethylene, J. Appl. Polym. Sci., 2009, vol. 111, pp. 1426-1432.

Ren, L., Men, L., Zhang, Z., Guan, F., Tian, J., Wang, B., Wang, J., Zhang, Y., and Zhang, W., Biodegradation of polyethylene by Enterobacter sp. D1 from the guts of wax moth Galleria mellonella, Int. J. Environ. Res. Publ. Health, 2019, vol. 16, art. 1941.

https://doi.org/10.3390/ ijerph16111941

Restrepo-Florez, J.M., Bassi, A., and Thompson, M.R., Microbial degradation and deterioration of polyethylene-a review, Int. Biodeterior. Biodegr., 2014, vol. 88, pp. 83-90.

Ribitsch, D., Heumann, S., Trotscha, E., Herrero Acero, E., Greimel, K., Leber, R., BirnerGruenberger, R., Deller, S., Eiteljoerg, I., Remler, P., Weber, T., Siegert, P., Maurer, K.H., Donelli, I., Freddi, G., et al., Hydrolysis of polyethylene-terephthalate by $p$-nitrobenzylesterase from Bacillus subtilis, Biotechnol. Prog., 2011, vol. 27, pp. 951-960.

Ribitsch, D., Herrero Acero, E., Greimel, K., Dellacher, A., Zitzenbacher, S., Marold, A., Rodriguez, R.D., Steinkellner, G., Gruber, K., Schwab, H., and Guebitz, G.M., A new esterase from Thermobifida halotolerans hydrolyses polyethylene terephthalate (PET) and polylactic acid (PLA), Polymers, 2012, vol. 4, pp. 617-629.

Riudavets, J., Salas, I., and Pons, M.J., Damage characteristics produced by insect pests in packaging film, J. Stored Prod. Res., 2007, vol. 43, pp. 564-570.

https://doi.org/10.1016/jj.jspr.2007.03.006

Rochman, C., Hoh, E., Kurobe, T., and Teh, S.J., Ingested plastic transfers hazardous chemicals to fish and induces hepatic stress, Sci. Rep., 2013, vol. 3, art. 3263. https://doi.org/10.1038/srep03263

Ronkvist, A.M., Xie, W.C., Lu, W.H., and Gross, R.A., Cutinase catalyzed hydrolysis of poly(ethylene terephthalate), Macromolecules, 2009, vol. 42, pp. 5128-5138.

Ru, J., Huo, Y., and Yang, Y., Microbial degradation and valorization of plastic wastes, Front. Microbiol., 2020, vol. 11, art. 442 .

https://doi.org/10.3389/fmicb.2020.00442

Sabev, H.A., Handley, P.S., and Robson, G.D., Fungal colonization of soil-buried plasticized polyvinyl chloride (pPVC) and the impact of incorporated biocides, Microbiology (Reading), 2006, vol. 152, pp. 1731-1739.

Sahebnazar, Z., Shojaosadati, S.A., MohammadTaheri, M., and Nosrati, M., Biodegradation of low-density polyethylene (LDPE) by isolated fungi in solid waste medium, Waste Manage., 2010, vol. 30, pp. 396-401.

https://doi.org/10.1016/j.wasman.2009.09.027

Santo, M., Weitsman, R., and Sivan, A., The role of the copper-binding enzyme-laccase-in the biodegradation of polyethylene by the actinomycete Rhodococcus ruber, Int. Biodeterior. Biodegr., 2013, vol. 84, pp. 204-210.

https://doi.org/10.1016/j.ibiod.2012.03.001

Sarmah, P. and Rout J., Efficient biodegradation of lowdensity polyethylene by cyanobacteria isolated from submerged polyethylene surface in domestic sewage water, Environ. Sci. Pollut. Res., 2018.

https://doi.org/10.1007/s11356-018-3079-7

Sazhin, B.I., Lobanov, A.M., Romanovskaya, O.S., Eidelnant, M.P., Koikov, S.N., Shuvaev, V.P., and Borisova, M.E., Elektricheskie svoistva polimerov (Electric Properties of Polymers), Sazhin, B.I., Ed., Leningrad: Khimiya, 1986.

Schmaltz, E., Melvin, E.C., Diana, Z., Gunady, E.F., Rittschof, D., Somarelli, J.A., Virdin, J., and Dunphy-Daly, M.M., Plastic pollution solutions: emerging technologies to prevent and collect marine plastic pollution, Environ. Int., 2020, vol. 144, p. 106067.

Sen, S. and Raut, S., Microbial degradation of low density polyethylene (LDPE): a review, J. Environ. Chem. Eng., 2015, vol. 3, pp. 462-473.

Sekhar, V.C., Nampoothiri, K.M., Mohan, A.J., Nair, N.R., Bhaskar, T., and Pandey, A., Microbial degradation of high impact polystyrene (HIPS), an e-plastic with decabromodiphenyl oxide and antimony trioxide, J. Hazard. Mater., 2016, vol. 318, pp. 347-354.

https://doi.org/10.1016/j.jhazmat.2016.07.008

Shah, A.A., Hasan, F., Hameed, A., and Ahmed, S., Biological degradation of plastics: a comprehensive review, Biotechnol. Adv., 2008, vol. 26, pp. 246-265.

https://doi.org/10.1016/j.biotechadv.2007.12.005

Sharma, S.R., Bioremediation of polythenes and plastics: a microbial approach, in Approaches in Bioremediation, Nanotechnology in the Life Sciences, Prasad, R. and Aranda, E., Eds., Springer Nature Switzerland AG, 2018, pp. 97-114.

Sheavly, S.B. and Register, K.M., Marine debris \& plastics: environmental concerns, sources, impacts and solutions, $J$. Polym. Environ., 2007, vol. 15, pp. 301-305.

Sheel, A. and Pant, D., Microbial depolymerization, in Waste Bioremediation, Energy, Environment, and Sustainability, Varjani, S.J., Gnansounou, E., Baskar, G., 
Pant, D., and Zakaria, Z.A., Eds., Springer Nature Singapore Pte Ltd., 2018, pp. 61-103.

Sheik, S., Chandrashekar, K.R., Swaroop, K., and Somashekarappa, H.M., Biodegradation of gamma irradiated low density polyethylene and polypropylene by endophytic fungi, Int. Biodeterior. Biodegr., 2015, vol. 105, pp. 21-29.

Shevlik, N.V., Stroganova, S.S., Tychinskaya, L.Yu., Koval', V.N., and Shcherbina, L.A., Synthesis and properties of amorphous light-transparent S-PET, Polymer. Mater. Tekhnol., 2016, vol. 2, pp. 35-46.

Shimpi, N., Mishra, S., and Kadam, M., Biodegradation of polystyrene (PS)-poly(lactic acid) (PLA) nanocomposites using Pseudomonas aeruginosa, Macromol. Res., 2012, vol. 20 , pp. $181-187$.

https://doi.org/10.1007/s13233-012-0026-1

Sielicki, M., Focht, D.D., and Martin, J.P., Microbial degradation of $\left[{ }^{14} \mathrm{C}\right]$ polystyrene and 1,3 -diphenylbutane, Can. J. Microbiol., 1978, vol. 2, pp. 798-803.

Silva, C., Da, S., Silva, N., Matama, T., Araujo, R., Martins, M., Chen, S., Chen, J., Wu, J., Casal, M., and Cavaco-Paulo, A., Engineered Thermobifida fusca cutinase with increased activity on polyester substrates, Biotechnol. J., 2011, vol. 6, pp. 1230-1239.

Sivan, A., Szanto, M., and Pavlov, V., Biofilm development of the polyethylene-degrading bacterium Rhodococcus ruber, Appl. Microbiol. Biotechnol., 2006, vol. 72, pp. 346352.

Skariyachan, S., Patil, A.A., Shankar, A., Manjunath, M., Bachappanavar, N., and Kiran, S., Enhanced polymer degradation of polyethylene and polypropylene by novel thermophilic consortia of Brevibacillus sp. and Aneurinibacillus sp. screened from waste management landfills and sewage treatment plants, Polym. Degrad. Stab., 2018, vol. 149, pp. 52-68.

https://doi.org/10.1016/j.polymdegradstab.2018.01.018

Song, Y., Qui, R., Hu, J., Zhang, X., Chen, Y., Wu, W.M., and He, D., Biodegradation and disintegration of expanded polystyrene by land snails Achatina fulica, Sci. Total. Environm., 2020, vol. 746, art. 141289.

Sowmya, H.V., Ramalingappa Krishnappa, M., and Thippeswamy, B., Biodegradation of polyethylene by Bacillus cereus, Adv. Polym. Sci. Technol. Int. J., 2014, vol. 4, pp. 2832.

Chemist's Handbook 21. Chemistry and Chemical Technology. https://www.chem21.info/.

Sudhakar, M., Doble, M., Murthy, P.S., and Venkatesan, R., Marine microbe-mediated biodegradation of low- and high-density polyethylenes, Int. Biodeterior. Biodegr., 2008, vol. 61, pp. 203-213.

https://doi.org/10.1016/j.ibiod.2007.07.011

Sulaiman, S., Yamato, S., Kanaya, E., Kim, J.J., Koga, Y., Takano, K., and Kanaya, S., Isolation of a novel cutinase homolog with polyethylene terephthalate degrading activity from leaf-branch compost by using a metagenomic approach, Appl. Environ. Microbiol., 2012, vol. 78, pp. 15561562.

https://doi.org/10.1128/AEM.06725-11

Tamnou, E.M.B., Arafo, A.T., Nougang, M.E., Metsopkeng, C.S., Ewoti, O.V.N., Moungang, L.M., Nana, P.A., Takang-Ettad, L.R.A., Perrière, F., Sime-Ngandoe, T., and Nola, M., Biodegradation of polyethylene by the bacterium Pseudomonas aeruginosa in acidic microcosm and effect of the environmental temperature, Environ. Challenges, 2021, vol. 3, e10056.

https://doi.org/10.1016/j.envc.2021.100056

Tanasupawat, S., Takehana, T., Yoshida, S., Hiraga, K., and Oda, K., Ideonella sakaiensis sp. nov., isolated from a microbial consortium that degrades poly(ethylene terephthalate), Int. J. Syst. Evol. Microbiol., 2016, vol. 66, pp. 2813-2818.

Taniguchi, I., Yoshida, S., Hiraga, K., Miyamoto, K., Kimura, Y., and Oda, K., Biodegradation of PET: current status and application aspects, ACS Catalysis, 2019, vol. 9, pp. 4089-4105.

Tischler, D., Microbial Styrene Degradation, Cham, Switzerland: Springer International Publishing, 2015, pp. 7-22.

Tokiwa, Y., Calabia, B.P., Ugwu, C.U., and Aiba, S., Biodegradability of plastics, Int. J. Mol. Sci., 2009, vol. 10, pp. 3722-3742.

https://doi.org/10.3390/ijms10093722

Tourova, T.P., Sokolova, D.S., Nazina, T.N., Gruzdev, D.S., and Laptev, A.B., Phylogenetic diversity of microbial communities from the surface of polyethylene terephthalate materials exposed to different water environments, Microbiology (Moscow). 2020, vol. 89, pp. 96-106.

Urgun-Demirtas, M., Singh, D., and Pagilla, K., Laboratory investigation of biodegradability of a polyurethane foam under anaerobic conditions, Polym. Degrad. Stabil., 2007, vol. 92, pp. 1599-1610.

Vertommen, M.A.M.E., Nierstrasz, V.A., van der Veer, M., and Warmoeskerken, M.M.C.G., Enzymatic surface modification of poly(ethyleneterephthalate), J. Biotechnol., 2005, vol. 120 , pp. 376-386.

Vimala, P.P. and Mathew, L., Biodegradation of polyethylene using Bacillus subtilis, Procedia Technol., 2016, vol. 24, pp. 232-239.

Volke-Sepúlveda, T., Saucedo-Castañeda, G., GutiérrezRojas, M., Manzur, A., and Favela-Torres, E., Thermally treated low density polyethylene biodegradation by Penicillium pinophilum and Aspergillus niger, J. Appl. Polym. Sci., 2002, vol. 83, pp. 305-314.

https://doi.org/10.1002/app.2245

Wang, X., Lu, D., Jönsson, L.J., and Hong, F., Preparation of a PET-hydrolyzing lipase from Aspergillus oryzae by the addition of bis(2-hydroxyethyl)terephthalate to the culture medium and enzymatic modification of PET fabrics, Eng. Life Sci., 2008, vol. 8, pp. 268-276.

Wang, Z., Ma, Z., and Li, L., Flow-induced crystallization of polymers: molecular and thermodynamic considerations, Macromolecules, 2016, vol. 49, pp. 1505-1517.

Webb, J.S., Nixon, M., Eastwood, I.M., Greenhalgh, M., Robson, G.D., and Handley, P.S., Fungal colonization and biodeterioration of plasticized polyvinyl chloride, Appl. Environ. Microbiol., 2000, vol. 66, pp. 3194-3200.

Webb, H., Arnott, J., Crawford, R., and Ivanova, E., Plastic degradation and its environmental implications with special reference to poly(ethylene terephthalate), Polymers, 2013, vol. 5, pp. 1-18.

Wei, R., Oeser, T., Then, J., Kuhn, N., Barth, M., Schmidt, J., and Zimmermann, W., Functional characterization and structural modeling of synthetic polyester-degrading hydrolases from Thermomonospora curvata, AMB Express, 2014, vol. 4, p. 44. 
Wei, R., Oeser, T., Schmidt, J., Meier, R., Barth, M., Then, J., and Zimmermann, W., Engineered bacterial polyester hydrolases efficiently degrade polyethylene terephthalate due to relieved product inhibition, Biotechnol. Bioeng., 2016, vol. 113, pp. 1658-1665. https://doi.org/10.1002/bit.25941

Wei, R. and Zimmermann, W., Microbial enzymes for the recycling of recalcitrant petroleum-based plastics: how far are we? Microb. Biotechnol., 2017a, vol. 10, p. 1308.

Wei, R. and Zimmermann, W., Biocatalysis as a green route for recycling the recalcitrant plastic polyethylene terephthalate, Microb. Biotechnol., 2017b vol. 10, pp. 13021307.

https://doi.org/10.1111/1751-7915.12714

Wei, W., Hao, Q., Chen, Zh., Bao, T., and Ni, B.-J., Polystyrene nanoplastics reshape the anaerobic granular sludge for recovering methane from wastewater, Water Res., 2020, vol. 182 , art. 116041

Woo, S., Song, I., and Joon Cha, H., Fast and facile biodegradation of polystyrene by the gut microbial flora of Plesiophthalmus davidis larvae, Appl. Environ. Microbiol., 2020, vol. 86. e01361-20.

https://doi.org/10.1128/AEM.01361-20

Wright, S.L. and Kelly, F.J., Plastic and human health: a micro issue?, Environ. Sci. Technol., 2017, vol. 51, pp. 6634-6647.

Wu, Q., Tao, H., and Wong, M.H., Feeding and metabolism effects of three common microplastics on Tenebrio molitor, Environ. Geochem. Health, 2019, vol. 41, pp. 17-26.

Yamada-Onodera, K., Mukumoto, H., Katsuyama, Y., Saiganji, A., and Tani, Y., Degradation of polyethylene by a fungus, Penicillium simplicissimum YK, Polym. Degrad. Stab., 2001, vol. 72, pp. 323-327.

Yang, J., Yang, Y., Wu, W.M., Zhao, J., and Jiang, L., Evidence of polyethylene biodegradation by bacterial strains from the guts of plastic-eating waxworms, Environ. Sci. Technol., 2014, vol. 48, pp. 13776-13784.

https://doi.org/10.1021/es504038a

Yang, Y., Yang, J., Wu, W.M., Zhao, J., Song, Y., Gao, L., Yang, R., and Jiang, L., Biodegradation and mineralization of polystyrene by plastic-eating mealworms: Part 1. Chemical and physical characterization and isotopic tests, Environ. Sci. Technol., 2015a, vol. 49, pp. 12080-12086.

Yang, Y., Yang, J., Wu, W.M., Zhao, J., Song, Y., Gao, L., Yang, R., and Jiang, L., Biodegradation and mineralization of polystyrene by plastic-eating mealworms: Part 2. Role of gut microorganisms, Environ. Sci. Technol., 2015b, vol. 49, pp. 12087-12093.

Yang, Y., Wang, J., and Xia, M., Biodegradation and mineralization of polystyrene by plastic-eating superworms $Z o$ phobas atratus, Sci. Total Environ., 2020, vol. 708, art. 135233.

https://doi.org/10.1016/j.scitotenv.2019.135233
Yanto, D.H.Y., Krishanti, N.P.R.A., Ardiati, F.C., Anita, S.H., Nugraha, I.K., Sari, F.P., Laksana, R.P.B., Sapardi, S., and Watanabe, T., Biodegradation of styrofoam waste by ligninolytic fungi and bacteria, IOP Conf. Series Earth Environ. Sci., 2019, vol. 308, art. 012001. https://doi.org/10.1088/1755-1315/308/1/012001

Yin, C.-F., Xu, Y., and Zhou, N.-Y., Biodegradation of polyethylene mulching films by a co-culture of Acinetobacter sp. strain NyZ450 and Bacillus sp. strain NyZ451 isolated from Tenebrio molitor larvae, Int. Biodeterior. Biodegrad., 2020, vol. 155, art.105089.

https://doi.org/10.1016/j.ibiod.2020.105089

Yoon, M.G., Jeon, J.H., and Kim, M.N., Biodegradation of polyethylene by a soil bacterium and $A l k B$ cloned recombinant cell, J. Bioremed. Biodegrad., 2012, vol. 3, art. 145.

Yoshida, S., Hiraga, K., Takehana, T., Taniguchi, I., Yamaji, H., Maeda, Y., Toyohara, K., Miyamoto, K., Zheng, Y., Yanful, E.K., and Bassi, A.S., A review of plastic waste biodegradation, Crit. Rev. Biotechnol., 2005, vol. 25, pp. 243-250.

Yoshida, S., Hiraga, K., Takehana, T., Taniguchi, I., Yamagi, H., Maeda, Y., Toyohara, K., Miamoto, K., Kimura, Y., and Oda, K., A bacterium that degrades and assimilates poly(ethylene terephthalate), Science, 2016, vol. 351, pp. 1196-1199.

Zakharov, V.A., Mikenas, T.B., Nikitin, V.E., and Mozgunova, N.V., Catalyst and method of obtaining ultra-high molecular polyethylene using this catalyst, Patent RU2346006, Byull. Izobr., 2009, no. 4.

Zhang, J., Wan, X., Gong, J., and Gu, Z., A study on the biodegradability of polyethylene terephthalate fiber and diethylene glycol terephthalate, J. Appl. Polym. Sci., 2004, vol. 93, pp. 1089-1096.

https://doi.org/10.1002/app.20556

Zheng, Y., Yanful, E.K., and Bassi, A.S., A review of plastic waste biodegradation, Crit. Rev. Biotechnol., 2005, vol. 25, pp. 243-250.

https://doi.org/10.1080/07388550500346359

Zheng, J. and Suh, S., Strategies to reduce the global carbon footprint of plastics, Nat. Clim. Chang., 2019, vol. 9, pp. $374-378$.

Zhurina, M.V., Gannesen, A.V., Martyanov, S.V., and Plakunov, V.K., Express method for determining the relation between polyethylene biocorrosion by Chromobacterium violaceum biofilms and their ability to form extracellular matrix, Microbiology (Moscow), 2020, vol. 89, pp. 44-49.

Zimmermann, W. and Billig, S., Enzymes for the biofunctionalization of poly(ethylene terephthalate), Adv. Biochem. Engin. Biotechnol., 2011, vol. 125, pp. 97-120.

Translated by D. Timchenko 